"نشريه علوم زراعى ايران"

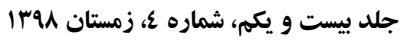

مقاله ب\$زوهشى

شناسايى هTL QTL اصلى و اييستاتيك صفات مرتبط با عملكرد دانه در جمعيت خويش آميخته

نوتر كيب برنج (Oryza sativa L.)

Identification of main and epistatic QTLs for grain yield related traits in a recombinant inbred lines population of rice (Oryza sativa $\mathbf{L}$.)

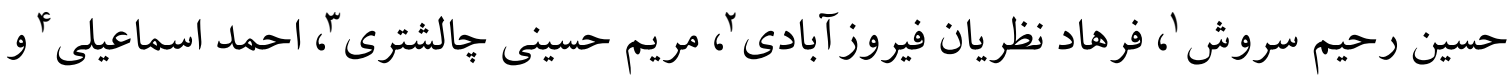 على اكبر عبادى ه
جـ

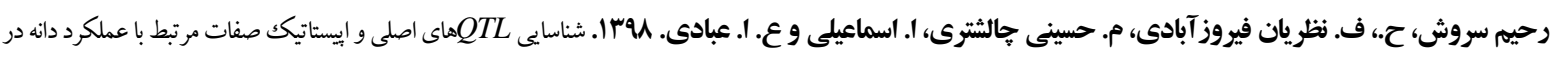

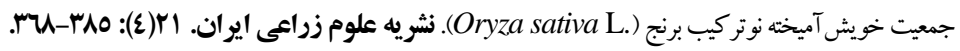

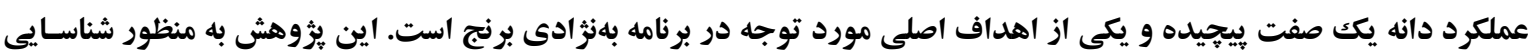
هاى اصلى و اييستاتيك عملكرد دانه و اجزاى عملكرد در يك جمعيت IRTL

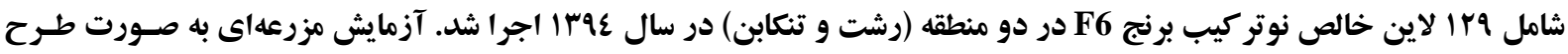

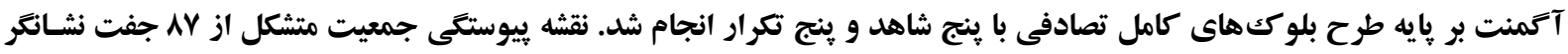

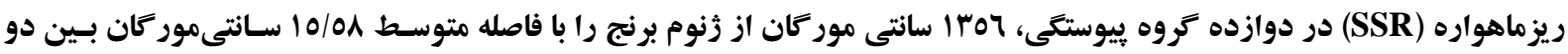

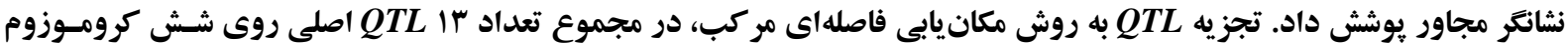

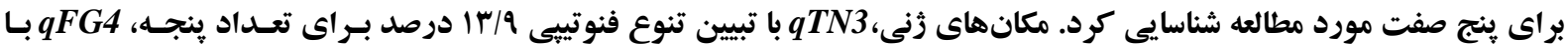

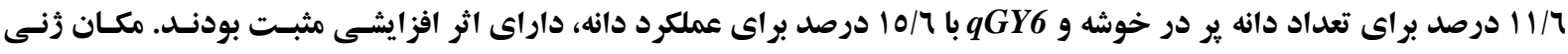

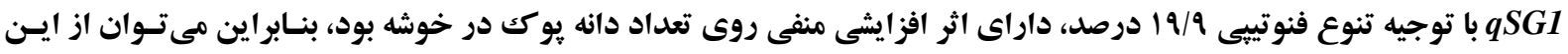

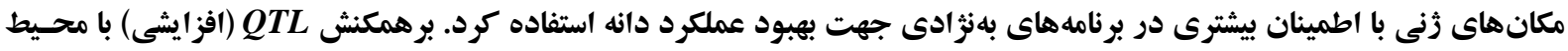

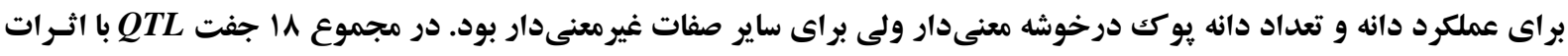

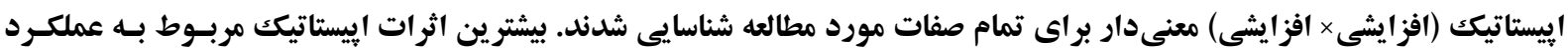

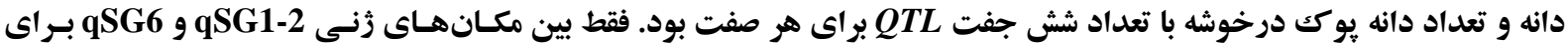

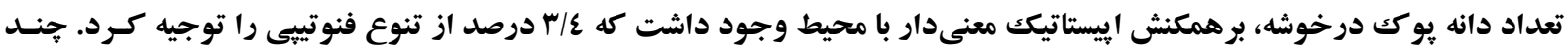

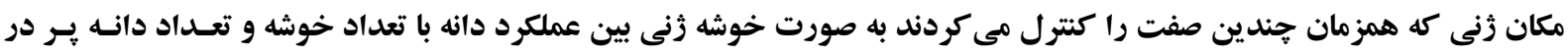

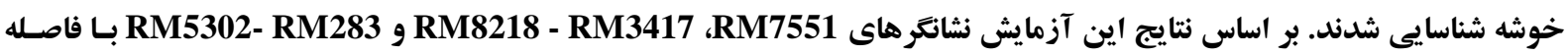

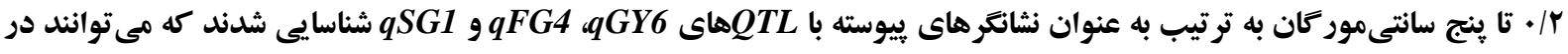

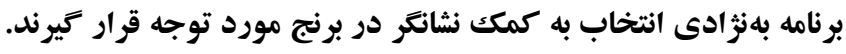

وازههاى كليدى: اييستازى، برنج، تنوع فنوتيبى، خوشه زنى و مكانيابى ذنى.

اين مقاله مستخرج از رساله دكترى نغارنده اول مى باشد.

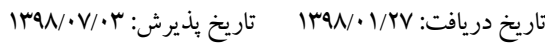

ا- إنشجوى دكترى دانشكده كشاورزى دانشكاه لرستان

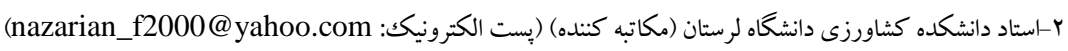

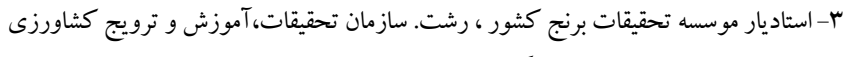
F- ب- دانشيار دانشكده كثاورزى دانشكاه لرستان

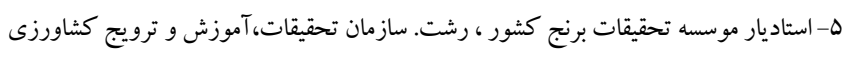


روى كروموزومهاى يكك و سـه بـراى تعـداد خوشـه در

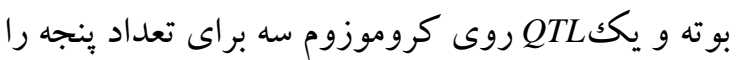

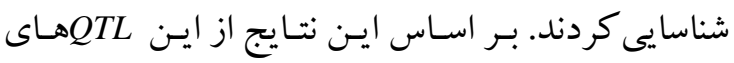

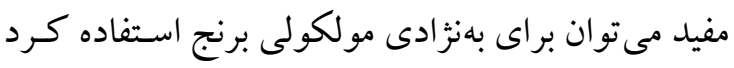

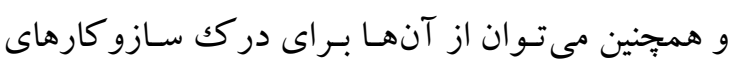
مولكولى بايه در برنج بهرهبردارى نمود.

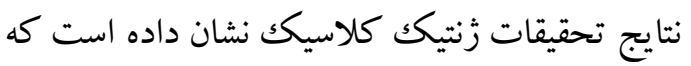
هم عامل زنتيكى (اثر افزايشى، اثر غالبيـت و اييستازى) و هم عامـل محيطى بـراى كنتـرل صـفات كمسى بسيار

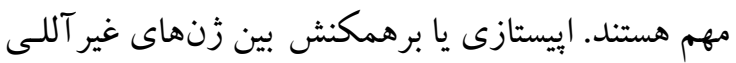

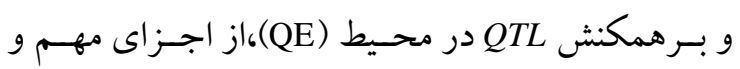

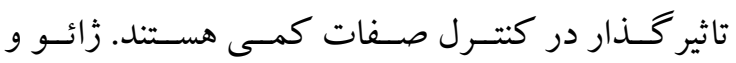

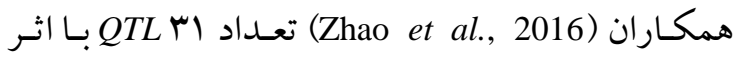
افزايشى براى اجزاى عملكرد برنج با الكوى بـرهمكنش إنش

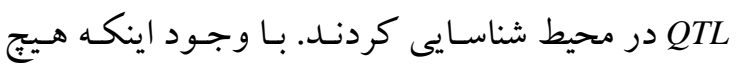
يكك از جهار QTL شناسـيى شـده بـراى تعـداد خوشـهـ داراى بـرهمكنش معنسى دار نبودنــا، تعـداد يـنج

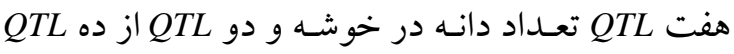
وزن هـزار دانسه، داراى بـرهمكنش افزايشى در محسيط

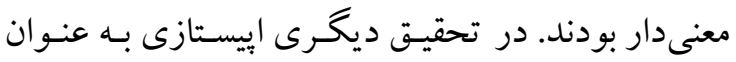

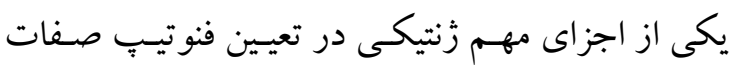

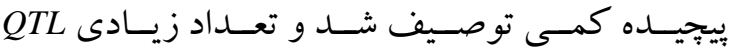

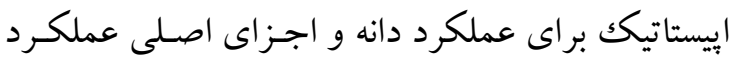

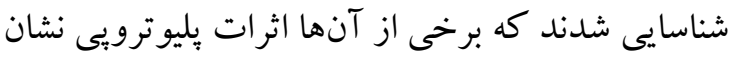
دادند (Wang et al., 2014). اثــرات إيسـتازى بـين QTLهــاى اصـلى معنسىدار

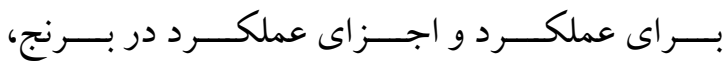
در جمعيتهــاى مختلـف زنتيكسى شناسـايى شــدهانـــ (Ye et al., 2009; Zhao et al., 2013) هدف بـر آورد اثرات اييستاتيكك و محيطى در كنترل

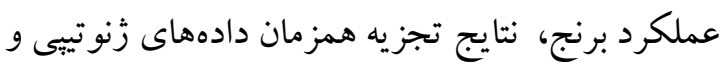

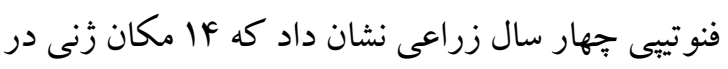

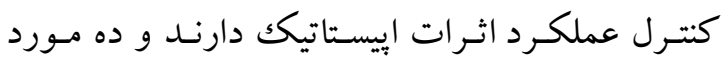

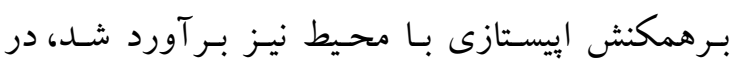

\section{مقدمه}

عملكرد برنج يكك صفت زراعسى ييجيـده اسـت كـه توسط زنهاى متعددى كنترل مىشود، اما اساسـا بـا سـهـ

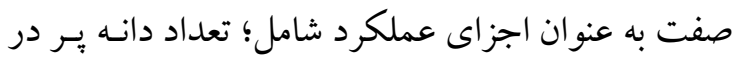
خوشه، تعداد خوشه در بوته و وزن هـز وار دانسه شناسـايى

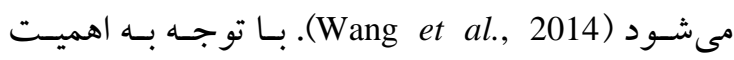

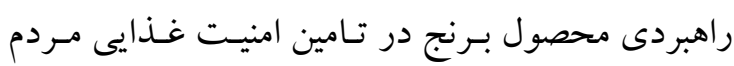

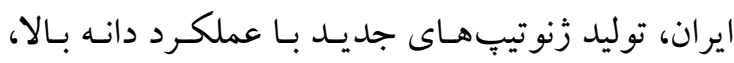

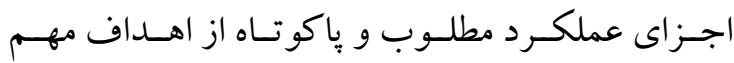

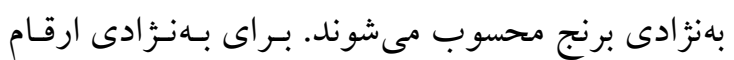

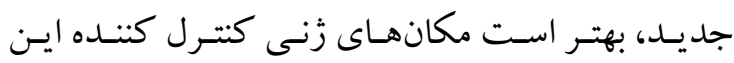

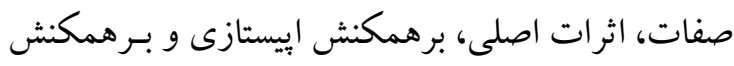

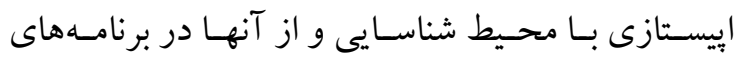

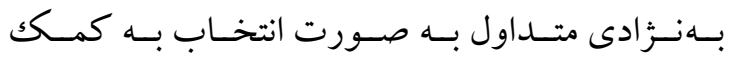

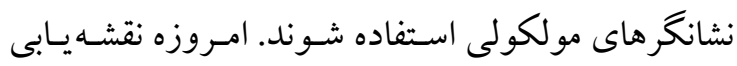

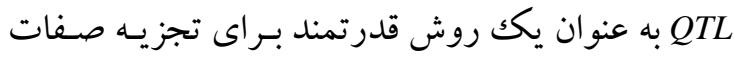

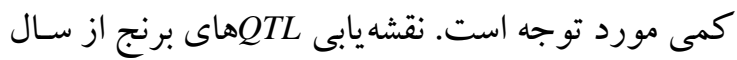

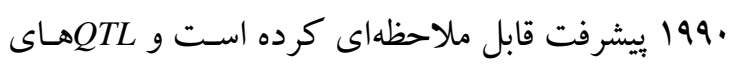

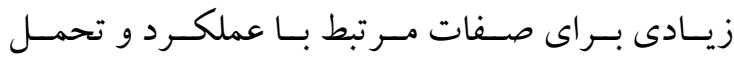
به تنشهاى محيطى در برنج شناسايى شدهانـد. تعـدادى رئس

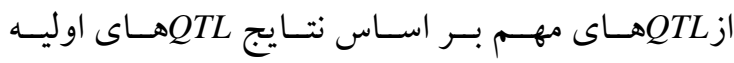

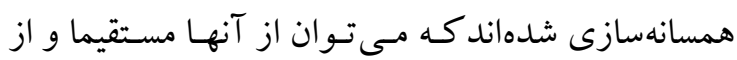

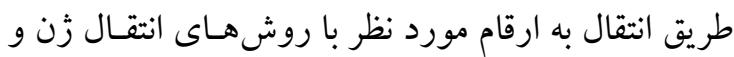

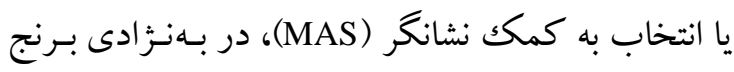
استفاده كرد (Wu et al., 2013).

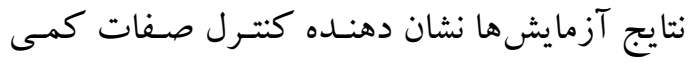

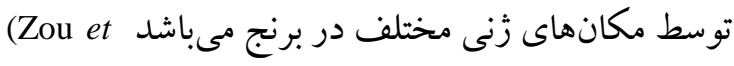
.al., 2005; You et al., 2006; Wang et al., 2014) سـينگك و همكـاران (Singh et al., 2017) عملكـرد و صـفات زراعسى بـرنج را در شـر ايط غرقـاب

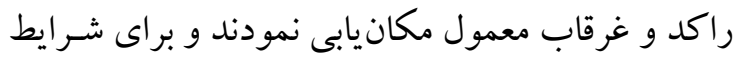

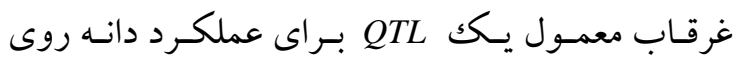
كرومـوزوم ب ا، جههار

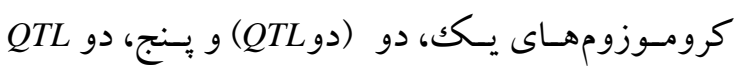




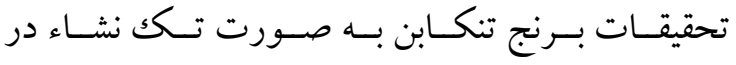

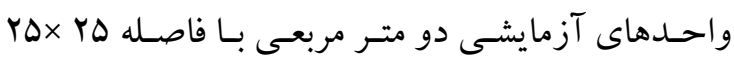

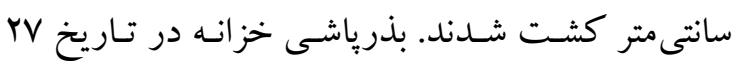
فروردين انجام شد. در طى فصل رشد صفات تعداد ينجه (تعـداد خوشهـ

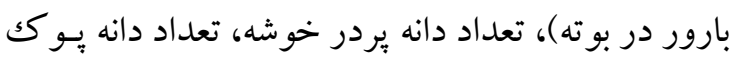

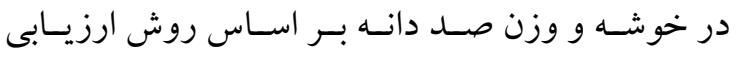

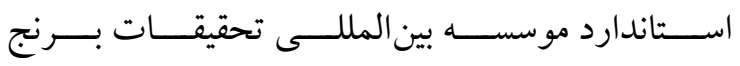
(Chaudhary, 1996)

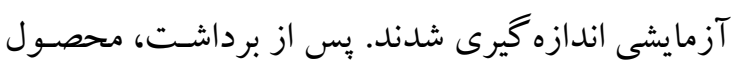

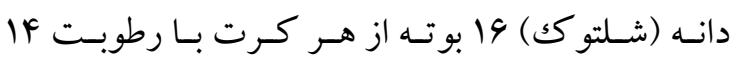

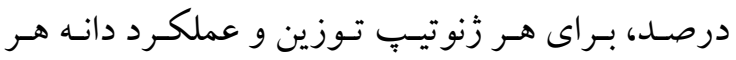

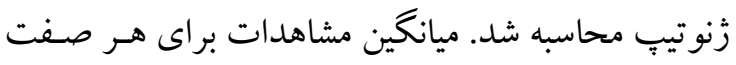

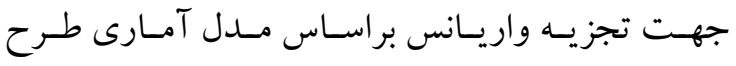

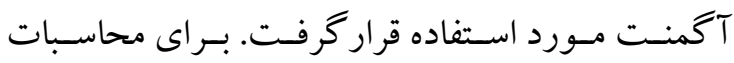
آمارى از نرم افزارهاى EXCEL و SAS استفاده شد.

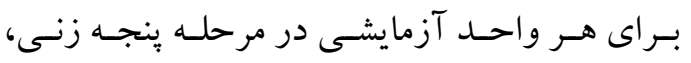

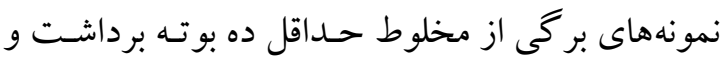

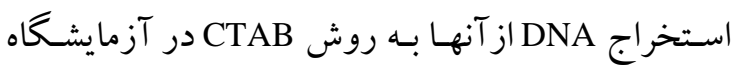
بيوتكنولوزى موسسه تحقيقات برنج- رشـت انجـام شـــ Murray and Thompson, 1980)

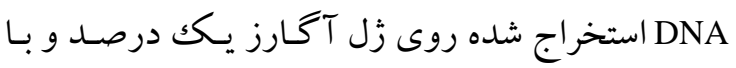
استفاده از الكتروفورز افقى و فاز ل تعيين كرديد. تعـداد

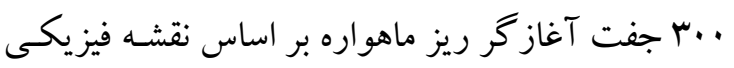

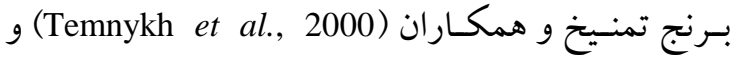
مـك كوش و همكـاران (McCouch et al., 2002) بـا

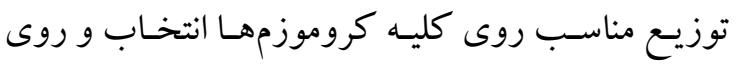

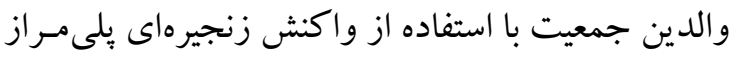

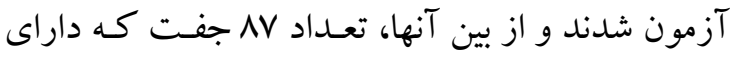

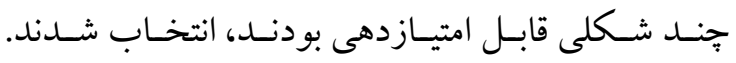

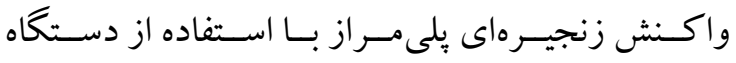
ترموسايكلر (T-Gradient, Biometra, USA) و در حجم

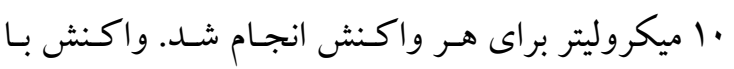
جرخه حرارتى شامل جهار دقيقه واسرشته سـازى اوليـه
حالى كه تعداد سا مكـان زنسى داراى اثرات إيستاتيكك

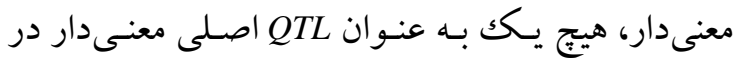
كنترل عملكرد شناسايى نشده بودند. اين موضـوع نشـان

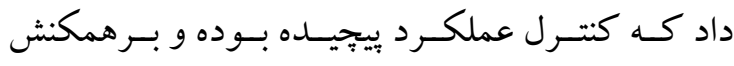

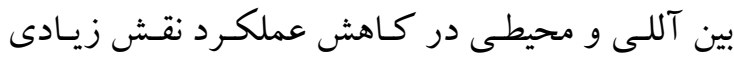

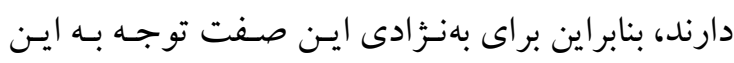

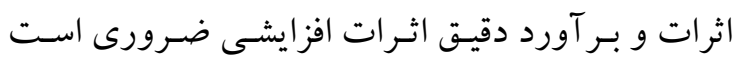

.(Hosseini Chaleshtari et al., 2014) در تحقيق حاضر با استفاده از يكك جمعيـت بيشـرفته حاصل از تلاقى رقم محلى على كاظمى با لايسن اصلاح

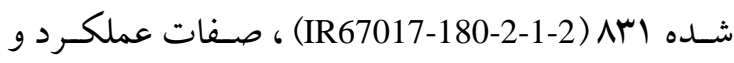
اجزاى عملكـرد بـرنج در دو مكـان؛ موسسـه تحقيقـات برنج (رشت) و ايستگاه تحقيقات برنج جَبر سر (تنكابن)

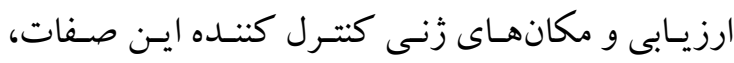

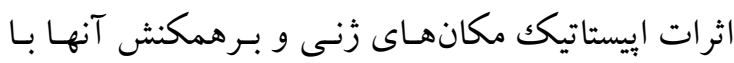

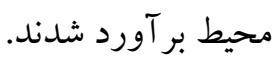

\section{مواد و روشها}

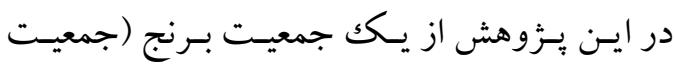

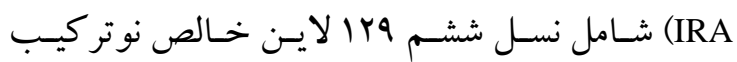
حاصل از تلاقى رقـم بـومى على كـاظمى (A) بـه عنـوان

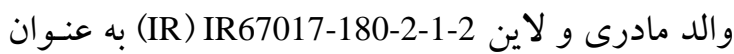

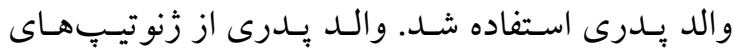
اصلاح شده موسسه بينالمللى تحقيقات برنج با عملكرد

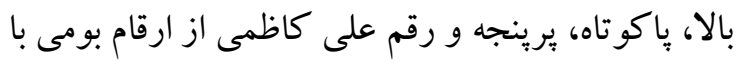

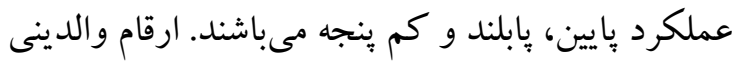

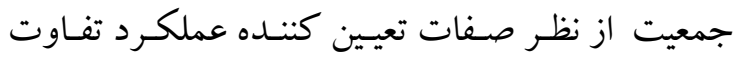

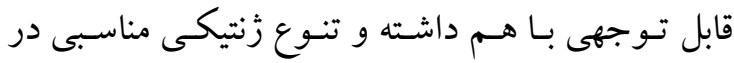

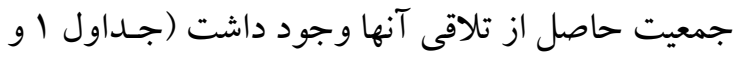

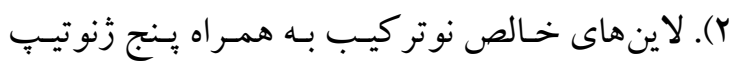

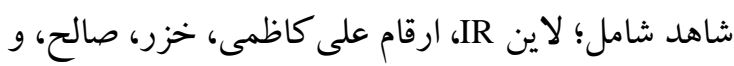

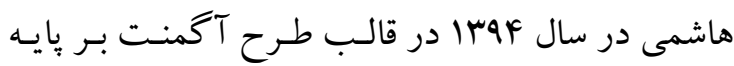

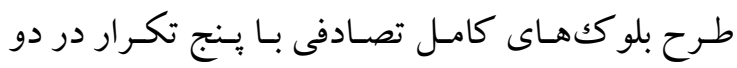

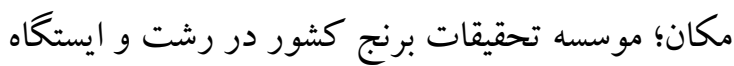




\section{نتايج و بحث}

نتايج تجزيه واريانس براى هـر مكـان نشـان داد كـه جمعيـت زنو تيبه هـاى خويش آميختسه نوتر كيـب (RIL)

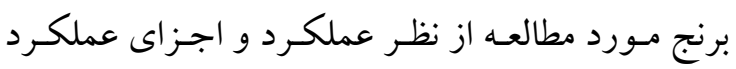

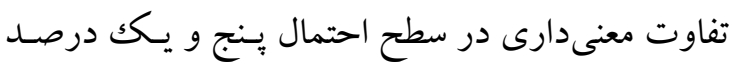

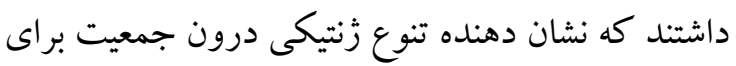

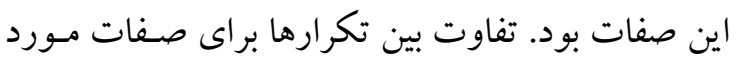

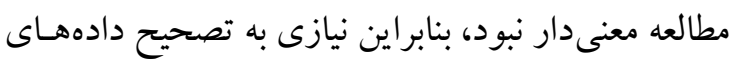

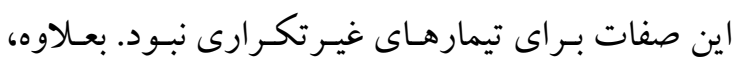
تنوع قابل ملاحظهاى در ميانخين صفات در بـين والـدين

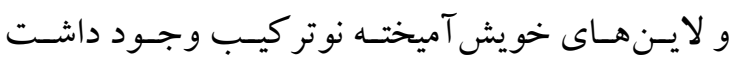

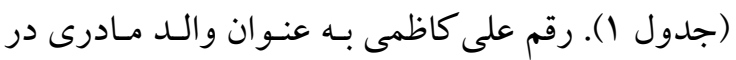

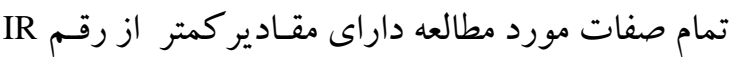

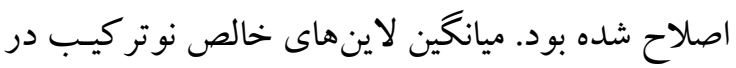

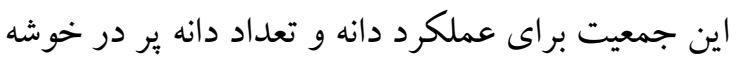

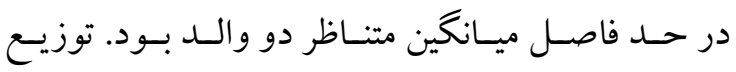

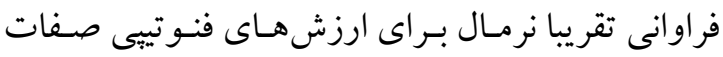
مورد مطالعه در لاين هاى RIL هـر دو جمعيـت مشـاهده

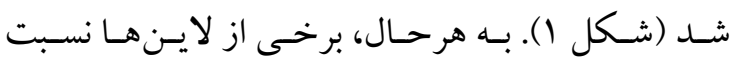

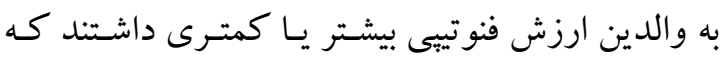
نشان دهنده وجود تفكيكك متجـاوز بـراى همـه صـفات بـود. دامنـه وسـيع تغييـرات دادههـاى صـفات در داخـل

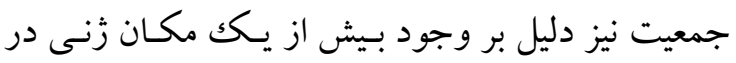

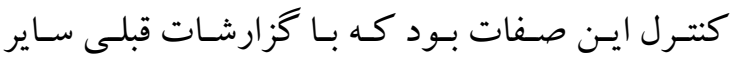
محققان در ايـن زمينه مطابقـت دارد Ye et al., 2009) .Hosseini Chaleshtari et al., 2012)

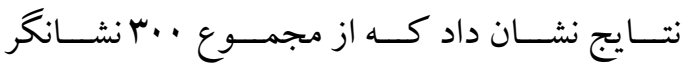

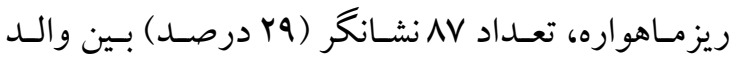

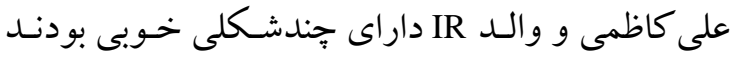

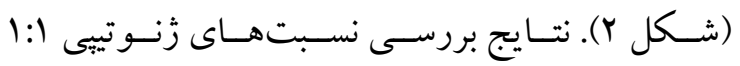

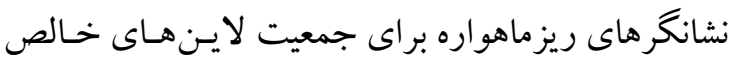

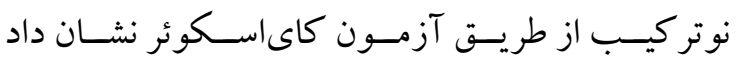

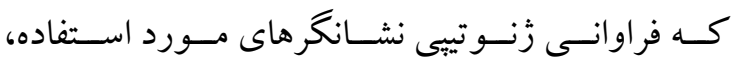

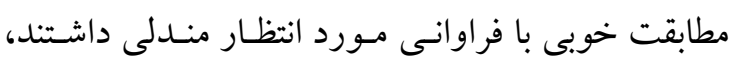

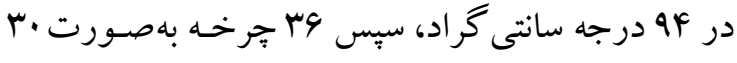
ثانيه واسر شته سازى در دماى FF

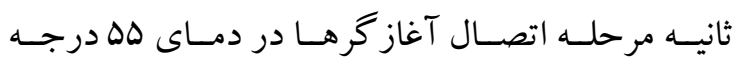

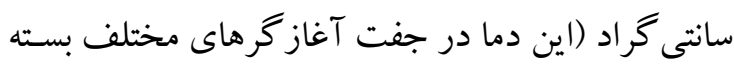

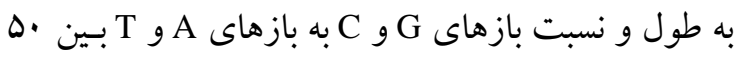

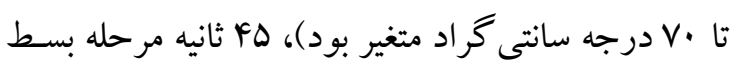

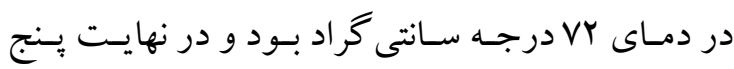

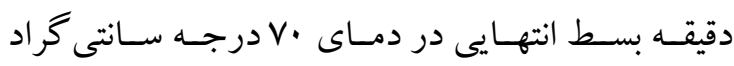
صورت گرفت (Rabiei et al., 2004).

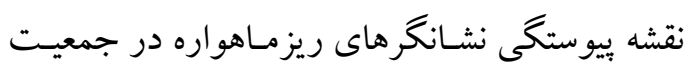
مورد مطالعه، با استفاده از دادههاى زنسوتييى AV نشـانكر

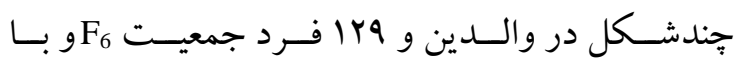
استفاده از نـرم افزار Map Manager مـانلى و همكـاران تهيه شد. فو اصل نشانكرى در اين (Manly et al., 2001)

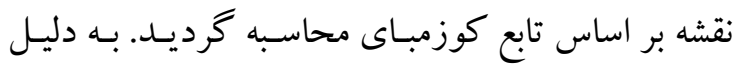

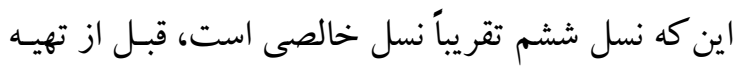

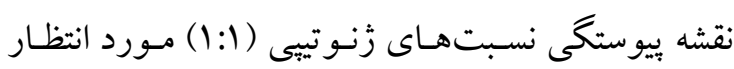

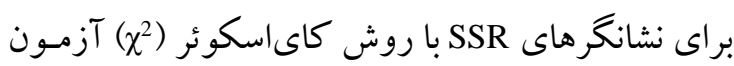

به منظور بـر آورد بهتر و دقيتق تـر مكانهـاى زنسى

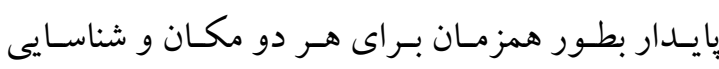

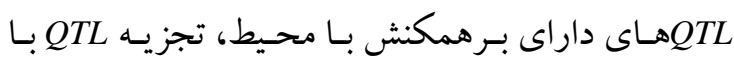

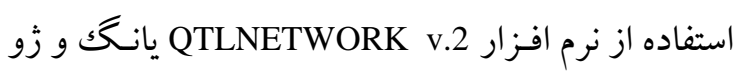
(Yang and Zhu, 2005) Markov Chain Monte دادههـا، بـه روش الخــوريتم Carlo (MCMC) (Wang et al., 1994; Satagopan et al., 1996) روش بـا اسـتفاده از مـدل تر كيبـى مكانيـابى فاصـلهاى

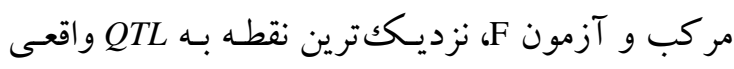

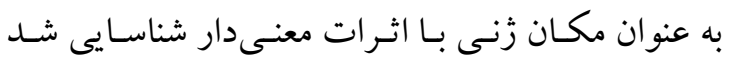

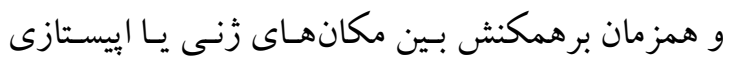

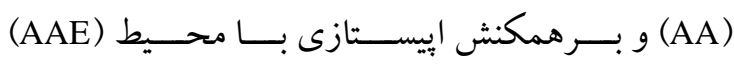

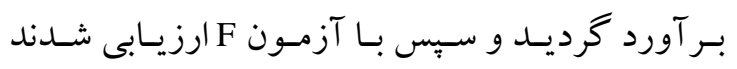
(Wang et al., 1999; Yang et al., 2008) 


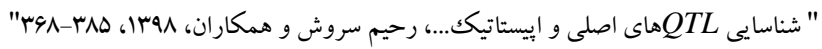

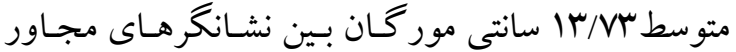

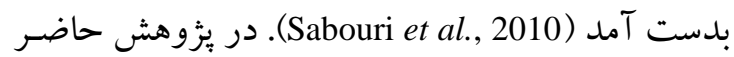
طول نقشه و فاصله بين نشانگرها در نقشه زرنتيكى ارائه

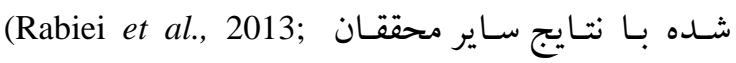
Rahimi et al., 2014)

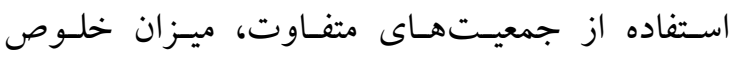

بنابراين از همه نشانكرهاى جندشكل جهـت تهيـه نقشـه ييوستخى و تجزيه QTL استفاده شد. طول كل نشـانگرها

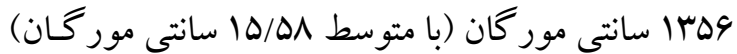

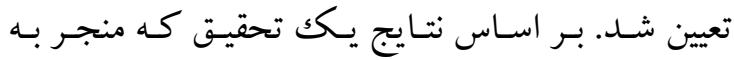

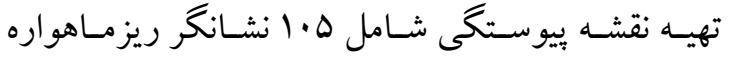
در جمعيت حاصـل از تلاقى ارقـام غريـب و سـيـيدرود

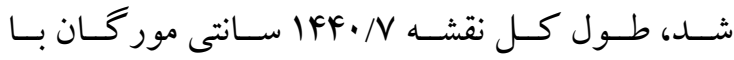

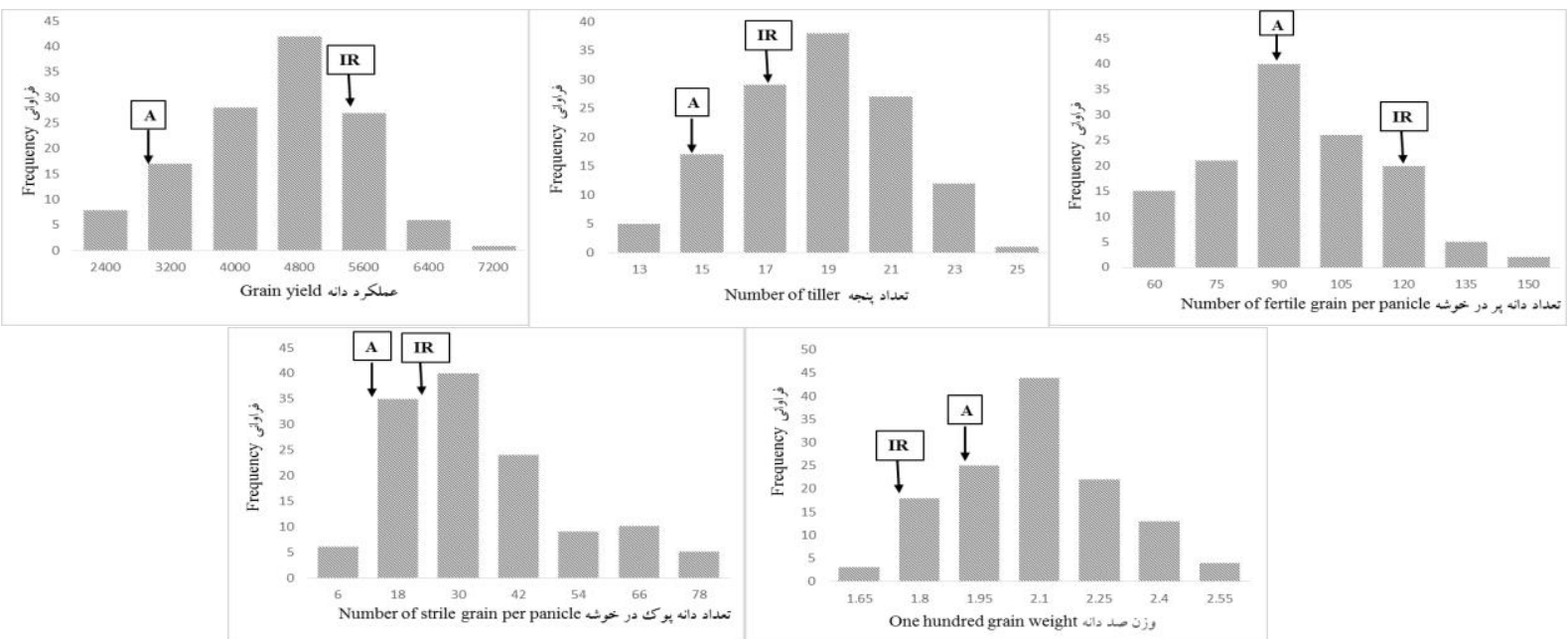

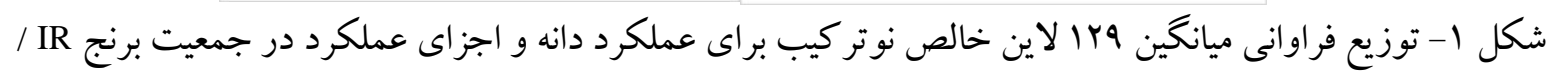

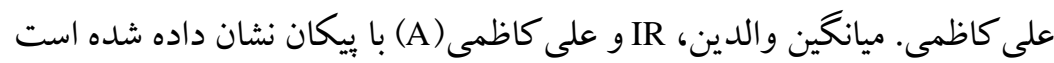

Fig. 1. Frequency distribution of the mean of 129 RILs for yield and yield components in Alikazemi/ IR rice population. The mean of parents, IR67017-180-2-1-2(IR) and Alikazemi (A) are shown by arrows

q qGY6، qGY4،qGY3-2 از بسين آنهـا مكـان زنس qGY6 روى كرومسوزوم شـش

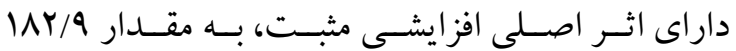

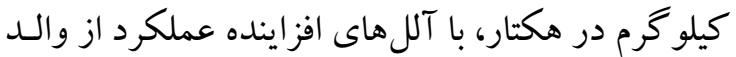

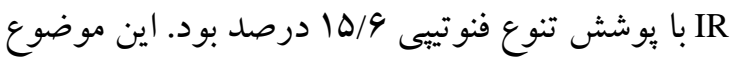

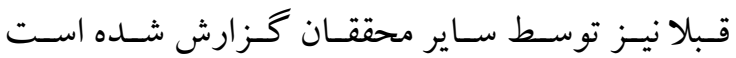
جهـار QThomson et al., 2003)

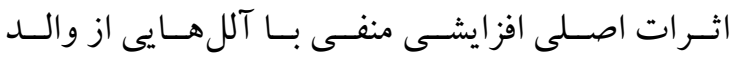

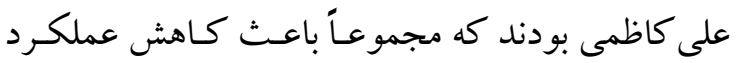

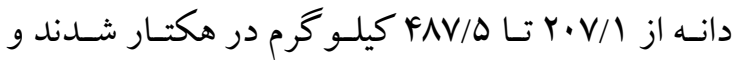

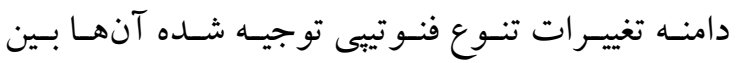

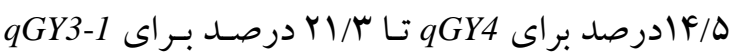

جمعيتها، نوع نشانخرهاى مورد اسـفاده، تعـداد افراد

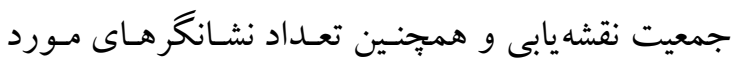
استفاده باشد. با توجه به استفاده از دادههاى حاصـل از نسـل Fo در تجزيه QTL، امكان بر آورد اثر غالبيـت وجـود نداشـت،

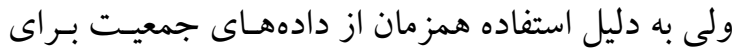
دو مكــان بـا استفاده از نرمافـزار NETWORK

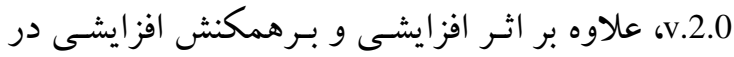

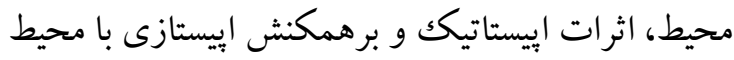

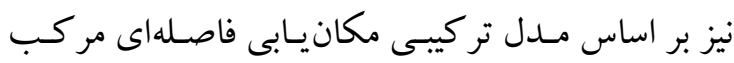

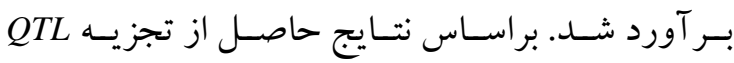

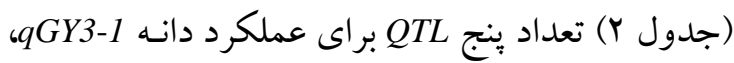


شــ (Zhang et al., 2018). تجزيـه همز مـان QTL بـراى دو سال در يكك جمعيت هاشمى / ندا منجر بـه شناسـايى

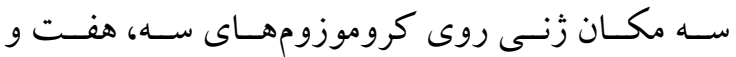

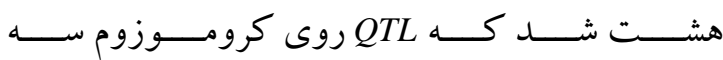

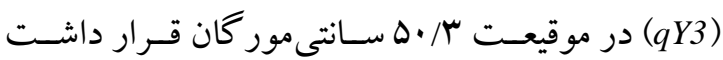
(Hosseini Chaleshtari et al., 2012) فاصـله · ا سـانتى مورگگتانى qGY3-2 تحقيـت حاضـر، يعنسى در ناحيـه كرومـوزومى بـين وGY3-1 و q و مكانيابى شد.
بود. مكان زنى $9 G Y 3-1$ ، بيشترين يوشش تنـوع فنـوتيبى

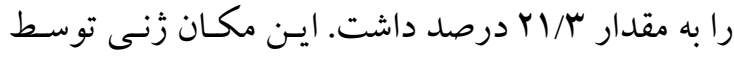
ساير محققـان نيـز روى كرومـوزوم سـه در ناحيـه نسـبتا

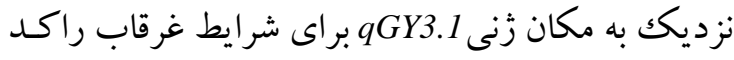
شاليزار برنج گزارش شـده اسـت (Singh et al., 2017). در تحقيق ديخرى يـك QTL QTY3) روى كرومـوزوم ســه بــين نشــانكرهاى RM282 و RM156 بــا توضـيح

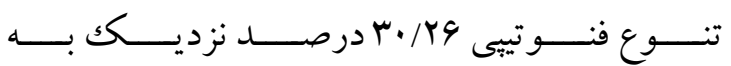
ناحيه كرومـوزومى qGY3-2 آزمـايش حاضـر، كـزارش

جدول ا- ميانكين، انحر اف معيار و دامنه تغييرات عملكرد و اجزاى عملكرد دانه در والدين و جمعيت IR/ على كاظمى برنج در دو مكان

Table 1. Mean, Mean \pm Standard error and range for yield and yield components in Alikazemi/ IR rice population and parents in two locations

\begin{tabular}{|c|c|c|c|c|c|}
\hline \multirow[b]{2}{*}{ Traits } & \multicolumn{2}{|c|}{ والدين Parents } & \multicolumn{3}{|c|}{ جمعيت IR67017-180-2-1-2 /على كاظمى (IRA population) } \\
\hline & $\begin{array}{c}\text { (على كاظمى } \\
\text { Alikazemi } \\
\end{array}$ & IR67017-180-2-1-2 & $\begin{array}{c}\text { د } 2 \\
\text { Range } \\
\end{array}$ & 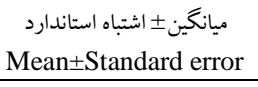 & LSD1 $(\%)$ \\
\hline $\begin{array}{l}\text { Grain yield (Yld) (kg.ha-1) } \\
\text { عملكرد دانه }\end{array}$ & 3069.5 & 5471.0 & 2394-6866 & $4256 \pm 701.6$ & 148.2 \\
\hline 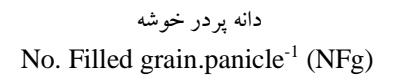 & 89.6 & 109.6 & $53.6-150.4$ & $94.6 \pm 14.4$ & 11.52 \\
\hline 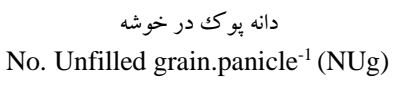 & 14.7 & 18.6 & 7.8-148.6 & $35.8 \pm 16.4$ & 2.88 \\
\hline تعداد ينجه & 15.4 & 17.6 & $12.7-24.4$ & $18.6 \pm 1.8$ & 1.17 \\
\hline $\begin{array}{c}\text { وزن صد دانه } 100 \text { Grain weight (Gw) (g) } \\
\end{array}$ & 2.51 & 2.6 & $1.8-3.3$ & $2.73 \pm 0.21$ & 0.06 \\
\hline
\end{tabular}

$$
\text { و يا بيوستخى سادهاى با يكديخر دارند. }
$$

بـرهمكنش افزايشـى در محسيط بــراى QTLهــاى عملكرد دانه واقع در كروموزومهاى سه (هر دو مـورد)، شـش و هشـت معنسى دار نبـود كـهـ ايسن موضسوع نشـان مى دهد تغييرات ناشى از اثر محيط، اثرات ايـن هTLهـا را بر عملكرد تغييـر قابـل ملاحظهـاى نمسىدهـد و نشـان دهنده يايدارى و مستقل بودن احتمـالى ايـن مكـانهـاى زنى از تاثير محيط مىباشد. با توجه به اثر افزايشى مثبت و معنى دار مكان زنى qGY6 مى تـوان از ايسن مكـانهـاى زنى با اطمينان بيشترى در برنامههاى بـهنزادى در جهـت بهبود عملكرد دانه استفاده كرد. دانشمندان معتقدند كـه ائه
در ايسن تحقيـق مكـان زنسى qGY8 روى كرومـوزوم هشت در فاصسله بـين نشـانكر هاى RM195-RM447 در إر

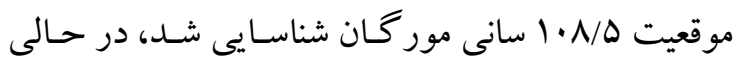

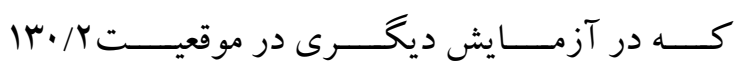

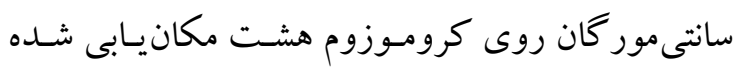
بود (Zhu et al., 2017) برخى از QTLهاى عملكرد دانه كه در اين تحقيق شناسايى شدند، قبلا در موقعيتهـاى مشابه به عنوان QTLهاى عملكرد در محيطهاى مختلف كزارش شدهاند. با ايسن حسال، تحقيقـات بيشـترى مانتـد نقشه يابى دقيق و همسـانه سـازى تعيين شود كه آيا آنها توسط همان زنها اداره مىشـوند 


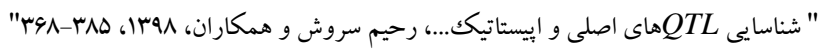

در محسيط رشـت بـه مقـدار ·ـ/ • ا كيلـو گرم درهكتـار كاهش داشت. محققان ديكرى نيز گزارش كردهاند كـه بيان QTLهاى موثر بر عملكرد دانـه و اجـزاى عملكـرد،

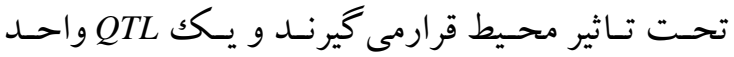

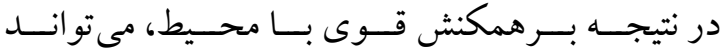
اثر متفاوتى درسالها و يا مكانهاى مختلف داشته باشـد (Xing et al., 2002) قبلا در ناحيه مجاور و نزديكك بـه qGYP-4 توسـط يـو و همكـاران (Yue et al., 2015) در شـر ايط محسدوديت نيتروزن، بين نشـانكر هاى RM273-RM241 مكانيسابى و با توجيه س/ه درصـد از تنـوع فـوتيىى، باعـث افـزايش عملكرد دانه گزارش شده است.
شناسايى QTLهايى كه به صورت پايسـار در محيطهـاى مختلف بيان مىشوند، در بهنزادى داراى اهميت بـوده و مطالعات بيشترى بر اي بررسى برهمكنش مورد نياز است (Wang et al., 2014). مكان زنسى qGY4 داراى بـرهمكنش معنى دار

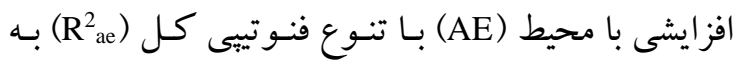
مقدار //ه درصـد بـود (جـدول Y). ايسن موضسوع نشـان مىدهد كه محسيطهـاى آزمـايش در تغييـرات عملكـرد دانسه از طريستق بـروز و بيـان ايسن QTL، بـهـ صـورت

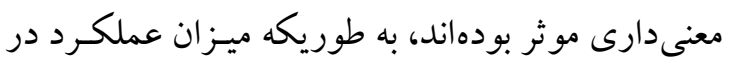

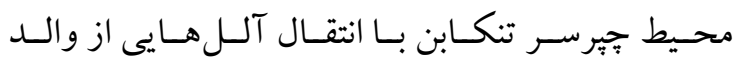

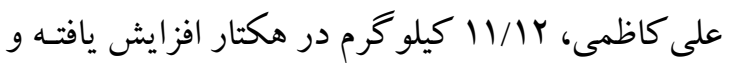
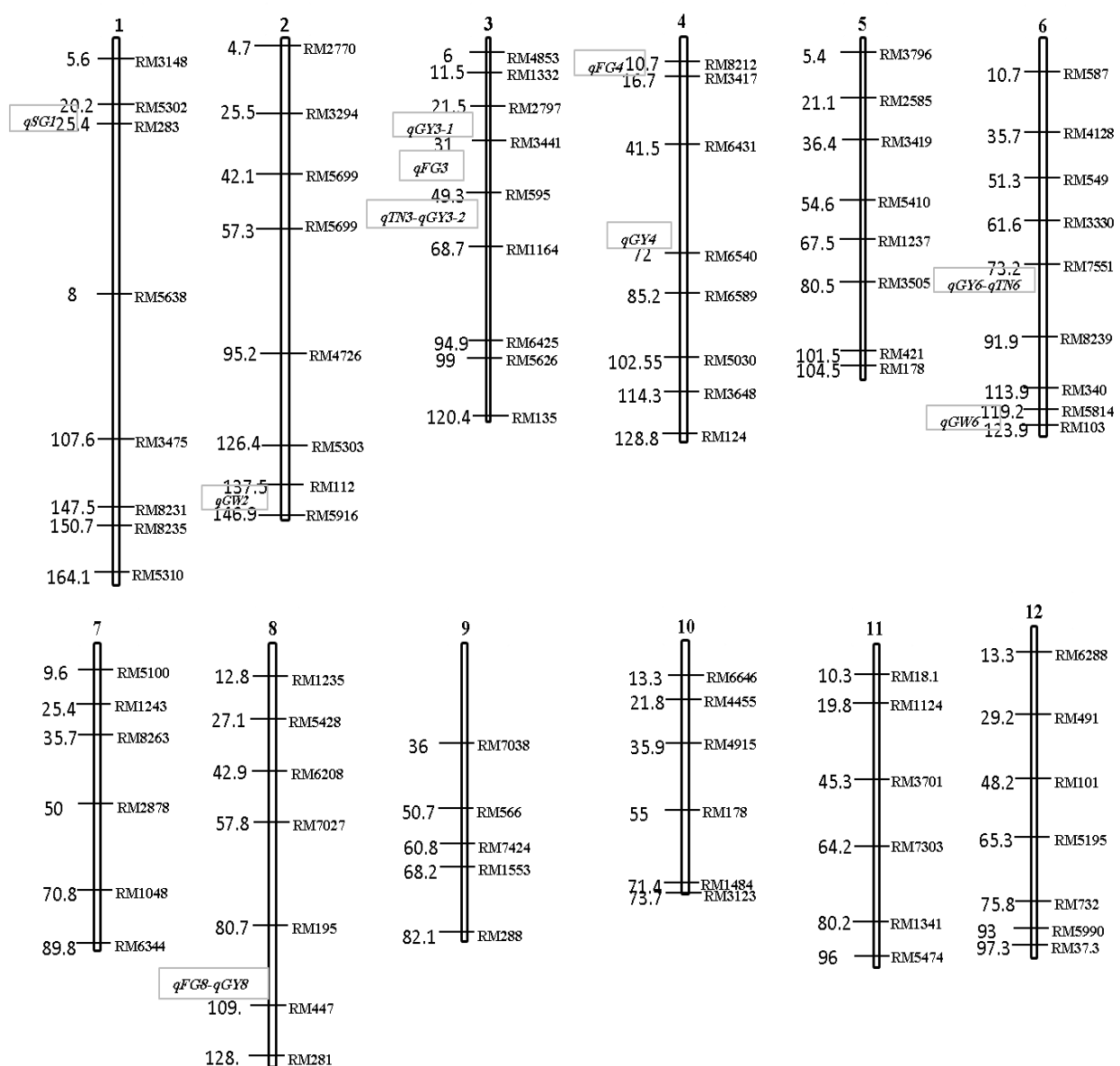

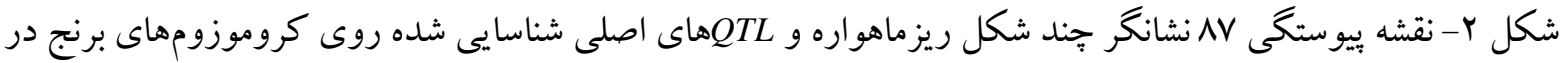
در جمعيت IRA حاصل از تلاقى رقم على كاظمى (A) و لاين بدرى (IR)

Fig. 2. Linkage map of 87 polymorph primers and identified main QTLs on rice chromosomes associated with grain yield and yield components in IRA population drived from a cross between Alikazemi (A) and parental IR line 


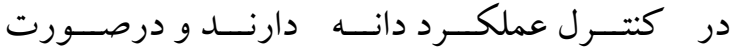
بر آورد آنها مىتوان اثرات افزايشى را با دقت بيشـترى بر آورد كرده و برنامههاى بهنزادى برنج را بـا هدفمنـدى دقيقتر براى افزايش عملكرد دانه تهيه و اجـرا كـرد. در تحقيق ديخرى در جمعيت بـرنج هاشـمى /IR-22 اثرات اييسـتازى بـين QTLهــاى 1لو و y6 1-2y و 1-5y، 1-2y و

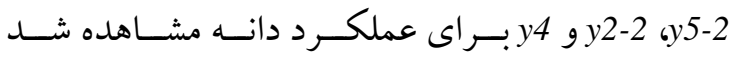
(Hosseini Chaleshtari et al., 2012) زنى دار ایى شش برهمكنش AA براى عملكرد دانه، فاقد

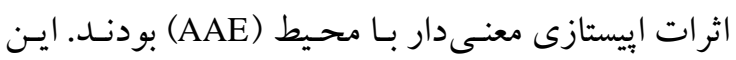
موضوع نشـان مىدهــ كـه منـاطق يـا محيطهـاى مـورد آزمايش تاثير قابل تـوجهى در بـروز و بيـان بـرهمكنش إيستازى بر اى عملكرد دانه نيستند. محققان ديخـرى نيـز كزارش كردند كه براى اين صفت در جمعيت هاشمى / ندا اثرات إيستازى با محيط بين QTLهـاى 33 و y8، yا و و y7 معنى دار نبوده است (Hosseini et al., 2012). تعداد سه QTL براى صفت تعداد دانسه يـر در خوشـه qFG4 qFG3 و qFG8 به ترتيـب روى كروموزومهـاى سه، جهار و هشت شناسايى شدند. مكان زنسى qFG4 در حدفاصل نشانكرهاى RM8218-RM7134 قرار داشت و و با يوشش تنوع فنوتيى 11/9 درصد و انتقال آلل هايى از والد IR داراى اثر افزايشى مثبت أ بود. بر اساس نتايج يكك تحقيق، مكانزنى qgn4 روى كروموزوم جهار بـين دو نشــانكر C820 و C933 در موقعيــت كرومــوزومى

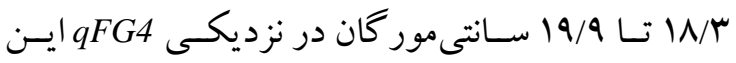
تحقيق قرار داشـت و هذ/ • درصـد از واريـانس فنـوتييى تعداد دانه در خوشه را تبيين كرد (Xing et al., 2002). دو مكــانزنى qFG3 و qFG8 بــهـ ترتيـبـ داراى تنــوع

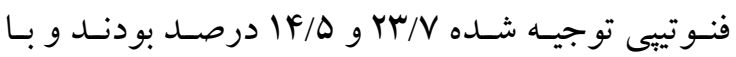
اثــــــافزايشــى على كاظمى براى كاهش اين صفت داشتند. هيج يك از

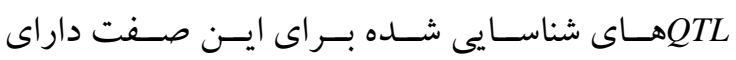
برهمكنش معنى دار با محسيط نبودنـــ. در آزمايشىى كـه

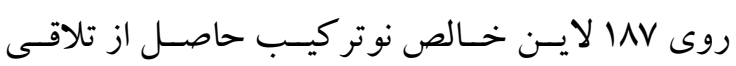

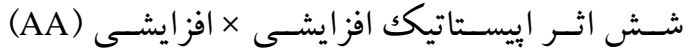
معنى دار براى عملكرد دانه شناسايى شـدند (جــدول ؟). جهار مورد از اثرات اييستازى بين مكانهـاى زنسى روى كروموزوم سه و مكانهـاى زنسى روى كرومـوزومهـاى هشت، جهار و شش مثبت بوده و آلل هايى از والد IR را

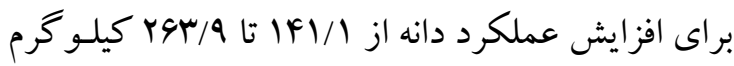

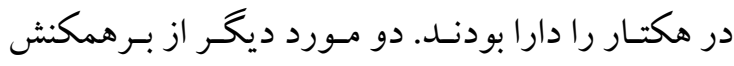
بين آللى منفى بودند و آللهاى را از والـد على كـاظمى براى كاهش عملكرد دانه داشتند. يوشش تنوع فنـوتييى

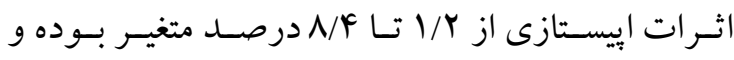

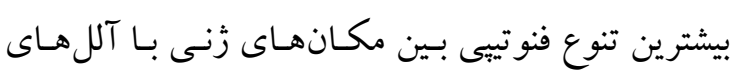
افزاينده عملكرد V/9 درصد بود.

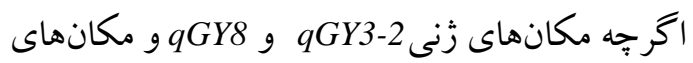
زنى

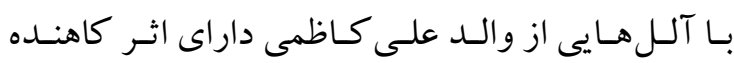
عملكرد دانه بودند، ولى اثر ابيستازى اين جفت هـLLLا مثبت بود و باعث افزايش عملكرد دانسه بـا آلـل هـايى از

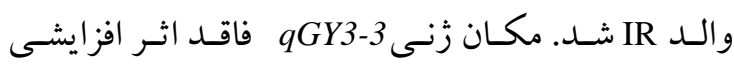
معنى دار و مكان زنى qGY4 با اثر اصلى منفى و كاهنده عملكرد، به مقدار Y.V/T كيلو گ Fرم در هكتار، در تعامـل

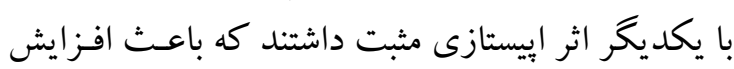
عملكرد دانه به مقـدار 194/9 كيلـو گرم در هكتـار شـد.

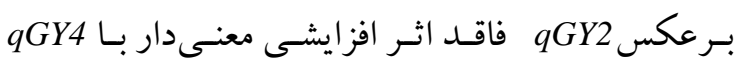

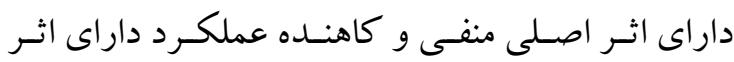

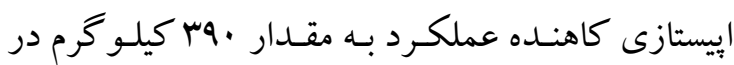

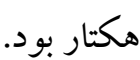
به نظر مىرسد كـه هـر يـك از QTLهـاى فاقـد اثـر اصلى و يا با اثر اصلى افزايشى منفى و يا مثبت، از طريق بـرهمكنش بـا سـاير مكـانهـاى زنسى، داراى اثـرات اييستازى معنى دار و موثر در كاهش و يا افزايش صفت، بويثز عملكرد دانه باشند و به همين دليل كنترل زنتيكى

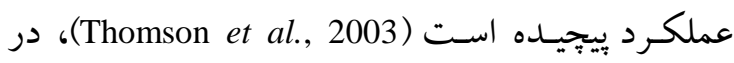
نتيجه نه تنها اثرات إيسـتازى، بلكـه بـرهمكنش QTL بـا محيط و برهمكنش اييستازى در محيط نيز نقش مهمسى 
كرومـوزوم جهـار، بـا واريـانس 19 دروصـد، شناسـايى كردند كه با qSG1 مطابقت ندارد ولى آن هم دارواي آنـ

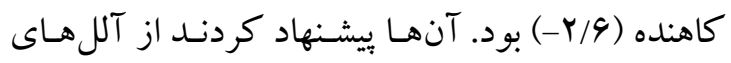

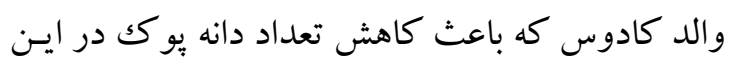

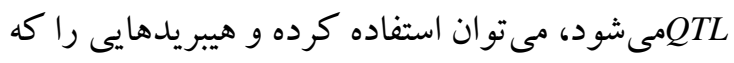

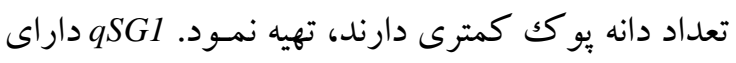

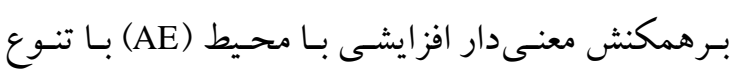

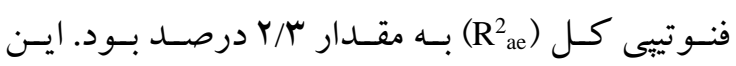

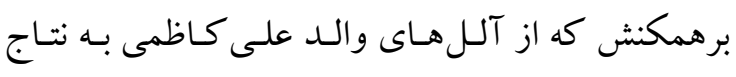

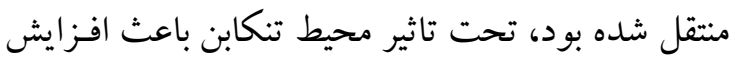

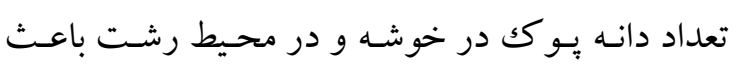
كاهش آن شد.

تعـداد شـش اثـر اييسـتازى بــراى تعـداد دانـه يـوكى

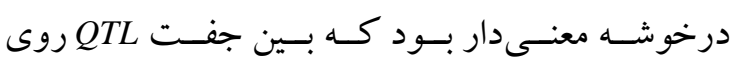

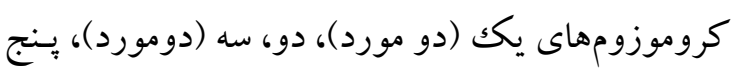

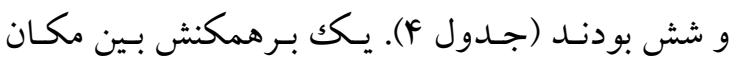

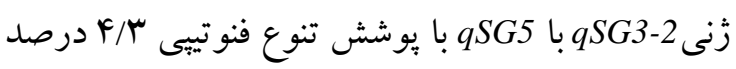

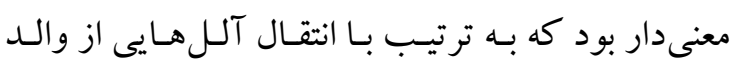
على كاظمى و IR به نتاج، موجب كاهش تعداد 9/9 د دانه

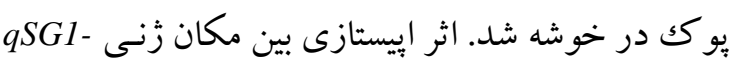

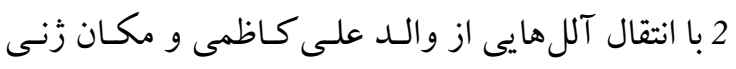

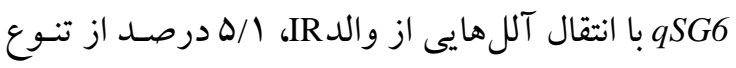

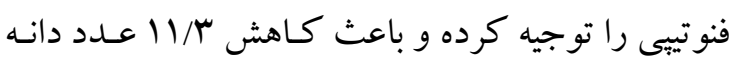

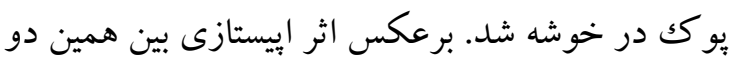

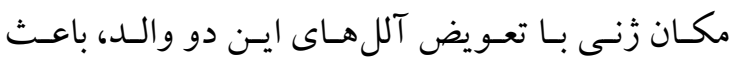

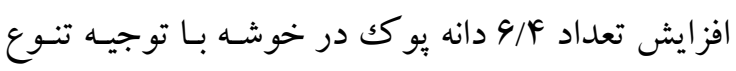

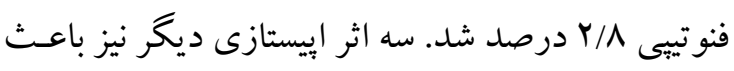

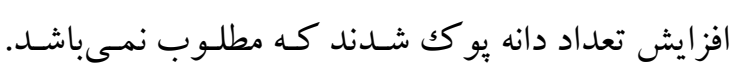

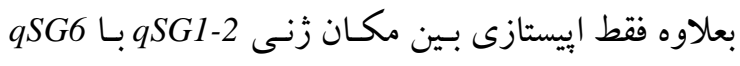

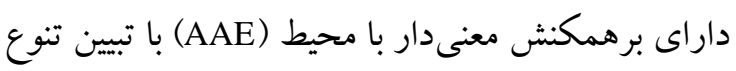

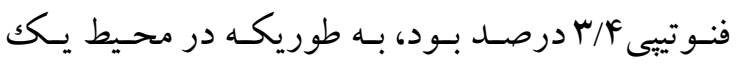

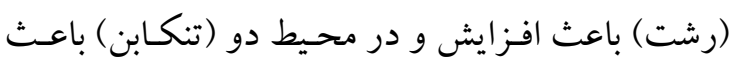

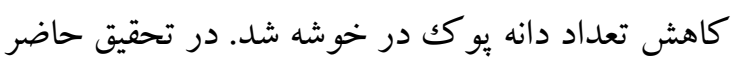

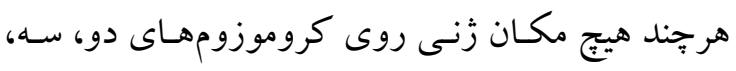

Zhenshan 97B و IRAT109 انجام شد، يكك مكان زنسى qSN8 براى تعداد دانه در خوشه بين نشانكر و RM149 و

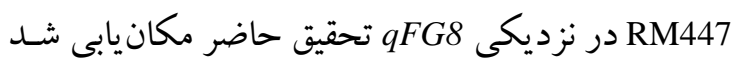

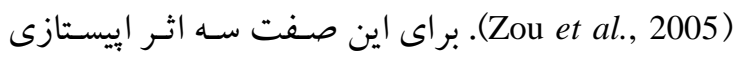

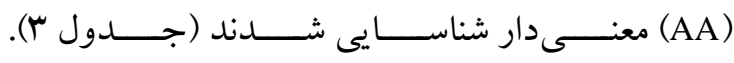

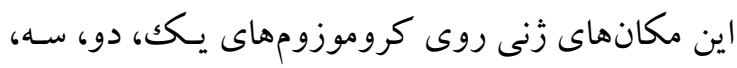

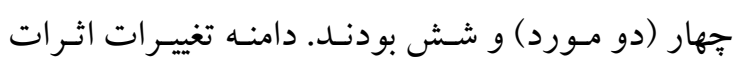

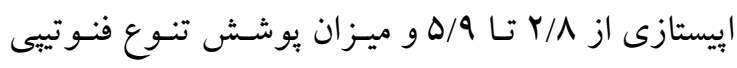

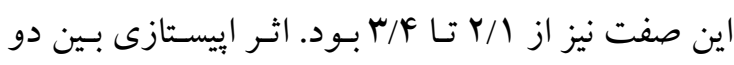
مكان زنى qFG1 و qFG6 و بين دو مكان زنس و

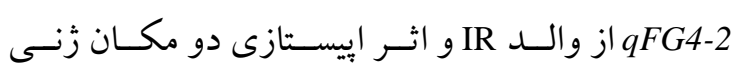
ديخر از والد على كاظمى منتقل شـدند. يسى و همكـاران

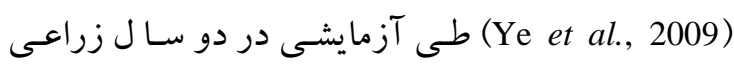

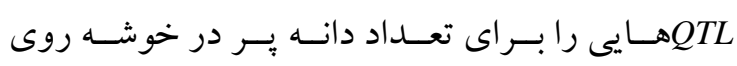
كروموزوم هاى يكك، سـه، يـنج، شـش، هفـت، ده و 11

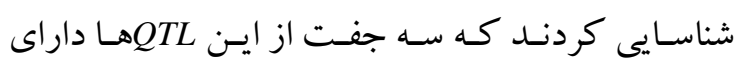

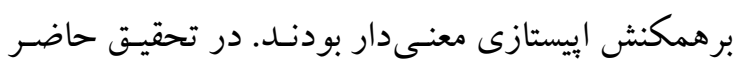

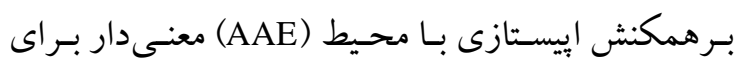

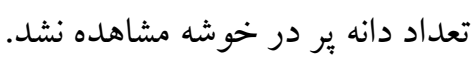
براى صفت تعداد دانه يو كك در خوشه، يـك مكـان

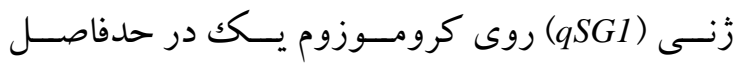

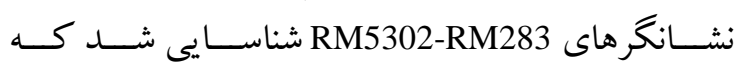

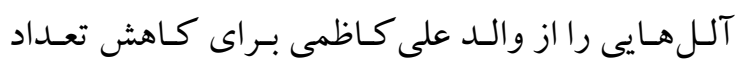

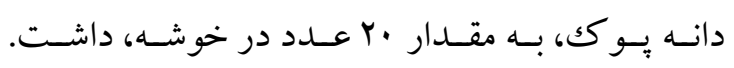

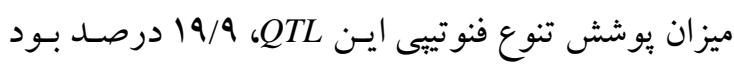

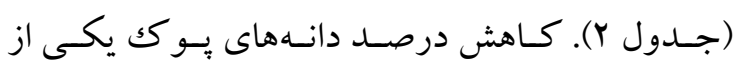

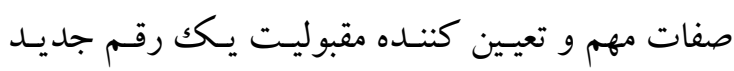

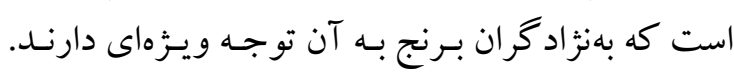

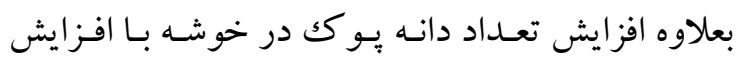

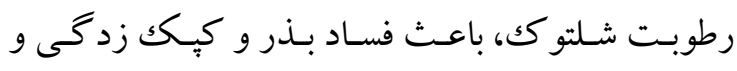

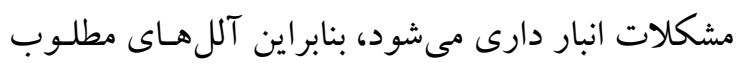
اين صفت را مى توان از والد على كاظمى به ارقام ديخـر

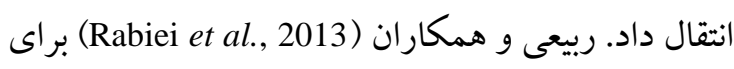

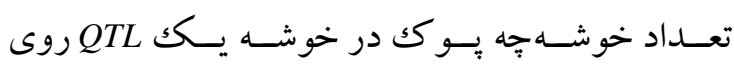


جدول r- بر آورد اثرات افزايشى و افز ايشى در محيط در مكانهاى زنى شناسايى شده عملكرد دانه و اجزاى عملكرد برنج در يكك جمعيت IR / على كاظمى در دو مكان

Table 2. Estimation of additive (A) and additive $\times$ environment (AE) interaction effects for identified QTLs associated with rice grain yield and yield components of

Alikazemi/IR population in two locations

\begin{tabular}{|c|c|c|c|c|c|c|c|c|c|}
\hline صفات گياهى & $Q T L$ & Marker interval & $Q T L$ position & $\mathrm{A}_{\mathrm{i}}$ & $\mathrm{R}_{\mathrm{a}}^{2}$ & $\mathrm{AE}_{1}$ & $\mathrm{AE}_{2}$ & $\mathrm{R}_{\mathrm{ae}}^{2}$ & Parent \\
\hline \multirow{5}{*}{$\begin{array}{c}\text { عملكرد دانه yield }\left(\mathrm{kg}^{2} \mathrm{ha}^{-1}\right) \\
\text { Grain }\end{array}$} & $q G Y 3-1$ & RM2791-RM3441 & 30.0 & -487.5 & 21.3 & - & - & - & A \\
\hline & $q G Y 3-2$ & RM5955-RM1164 & 60.3 & -291.1 & 16.6 & - & - & - & A \\
\hline & $q G Y 4$ & RM6431-RM6540 & 70.2 & -207.1 & 14.5 & 11.2 & -10.30 & 5.8 & A \\
\hline & $q G Y 6$ & RM7551-RM8239 & 75.8 & 182.9 & 15.6 & - & - & - & IR \\
\hline & $q G Y 8$ & RM195-RM447 & 108.5 & -338.4 & 18.5 & - & - & - & A \\
\hline \multirow{3}{*}{$\begin{array}{c}\text { دانه ير در خوشه.panicle }{ }^{-1} \\
\text { No. Filled grain.p }\end{array}$} & $q F G 3$ & RM3441-RM5955 & 35.5 & -24.7 & 23.7 & - & - & - & $\mathrm{A}$ \\
\hline & $q F G 4$ & RM8218-RM7134 & 11.7 & 4.1 & 11.6 & - & - & - & IR \\
\hline & $q F G 8$ & RM195-RM447 & 108.5 & -6.5 & 14.5 & - & - & - & $\mathrm{A}$ \\
\hline 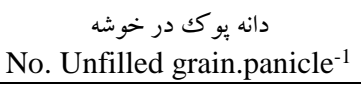 & $q S G 1$ & RM5302-RM283 & 25.2 & -20.0 & 19.9 & 0.34 & -0.24 & 2.2 & A \\
\hline تعداد ينجه & $q T N 3$ & RM5955-RM1164 & 60.3 & 3.8 & 13.9 & - & - & - & IR \\
\hline No. Tillers & qTN6 & RM7551-RM8239 & 75.8 & -1.5 & 11.6 & - & - & - & A \\
\hline وزن صد دانه & $q G W 2$ & RM112-RM5916 & 140.0 & -0.16 & 17.9 & - & - & - & A \\
\hline 100 Grain weight $(\mathrm{g})$ & $q G W 6$ & RM5814-RM103 & 120.8 & -0.17 & 19.6 & - & - & - & $\mathrm{A}$ \\
\hline
\end{tabular}

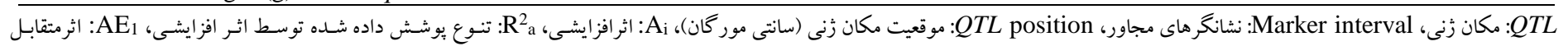

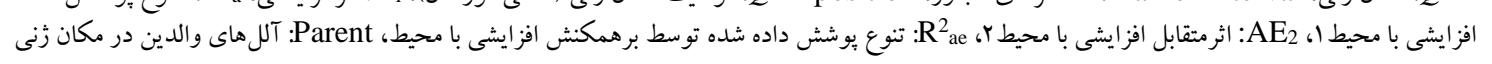


جدول ب- بر آورد اثرات إيستازى و إيستازى در محيط در مكانهاى زنى شناسايى شده صفات عملكرد و اجزاى عملكرد دانه از يك جمعيت IR / على كاظمى در دو مكان

Table 3. Estimation of epistasis (AA) and epistasis $\times$ environment (AAE) interaction effects for identified QTLs associated with rice grain yield and yield components of

Alikazemi/IR population in two locations

\begin{tabular}{|c|c|c|c|c|c|c|c|c|c|c|c|c|c|}
\hline Traits & $Q T L_{i}$ & Marker interval & $Q T L$ position & Parent & $Q T L_{j}$ & Marker interval & $Q T L$ position & Parent & $\mathrm{AA}$ & $\mathrm{R}_{\mathrm{aa}}^{2}$ & $\mathrm{AAE}_{1}$ & $\mathrm{AAE}_{2}$ & $\mathrm{R}_{\text {aae }}^{2}$ \\
\hline \multirow{7}{*}{$\begin{array}{c}\text { عملكرد دانه } \\
\text { Grain yield }\left(\mathrm{kg} \cdot \mathrm{ha}^{-1}\right)\end{array}$} & $q G Y 3-2$ & RM2791-RM3441 & 30.0 & IR & $q G Y 3-3$ & RM5955-RM1164 & 65.3 & A & -261.0 & 8.4 & - & - & - \\
\hline & $q G Y 3-2$ & RM2791-RM3441 & 30.0 & IR & $q G Y 8$ & RM195-RM447 & 108.5 & IR & 263.9 & 7.9 & - & - & - \\
\hline & $q G Y 3-3$ & RM5955-RM1164 & 65.3 & IR & $q G Y 4$ & RM6431-RM6540 & 58.2 & IR & 141.1 & 4.1 & - & - & - \\
\hline & $q G Y 3-3$ & RM5955-RM1164 & 65.3 & IR & $q G Y 6$ & RM7551-RM8239 & 90.8 & IR & 175.6 & 5.4 & - & - & - \\
\hline & $q G Y 2$ & RM3294-RM5699 & 25.5 & A & $q G Y 4$ & RM6431-RM6540 & 58.2 & IR & -390.0 & 1.2 & - & - & - \\
\hline & $q G Y 3-1$ & RM4853-RM1332 & 8.5 & IR & $q G Y 4$ & RM6431-RM6540 & 58.2 & IR & 193.6 & 6.1 & - & - & - \\
\hline & $q F G 3$ & RM3441-RM5955 & 35.5 & A & $q F G 4-1$ & RM8218-RM3471 & 11.7 & A & 5.9 & 3.4 & - & - & - \\
\hline \multirow{4}{*}{$\begin{array}{c}\text { دانه يِر در خوشه } \\
\text { No. Filled grain.panicle }\end{array}$} & $q F G 1$ & RM5302-RM283 & 23.2 & IR & $q F G 6$ & RM3330-RM7551 & 67.6 & IR & 3.2 & 2.9 & - & - & - \\
\hline & $q F G 2$ & RM112-RM5916 & 140.0 & IR & $q F G 4-2$ & RM3648-RM124 & 124.3 & IR & 2.8 & 2.1 & - & - & - \\
\hline & $q S G 1-1$ & RM5302-RM283 & 25.2 & IR & $q S G 2$ & RM2770-RM3294 & 12.13 & IR & 7.2 & 3.1 & - & - & - \\
\hline & $q S G 1-1$ & RM5302-RM283 & 25.2 & IR & $q S G 6$ & RM340-RM5814 & 116.6 & IR & 7.5 & 3.2 & - & - & - \\
\hline \multirow{4}{*}{$\begin{array}{c}\text { دانه يوك در خوشه } \\
\text { No. Unfilled grain.panicle }{ }^{-1}\end{array}$} & $q S G 1-2$ & RM5638-RM3475 & 103.6 & A & $q S G 6$ & RM340-RM5814 & 116.6 & IR & -11.3 & 5.1 & 2.1 & -2.3 & 3.4 \\
\hline & $q S G 3-1$ & RM1332-RM2791 & 11.5 & IR & $q S G 5$ & RM3505-RM421 & 102.1 & IR & 8.1 & 3.2 & - & - & - \\
\hline & $q S G 3-2$ & RM5955-RM1164 & 63.3 & A & $q S G 5$ & RM3505-RM421 & 102.1 & IR & -9.9 & 4.3 & - & - & - \\
\hline & $q S G 6$ & RM549-RM3330 & 60.3 & $\mathrm{~A}$ & $q S G 1-2$ & RM5990-RM3739 & 95.5 & $\mathrm{~A}$ & 6.4 & 2.8 & - & - & - \\
\hline \multirow{3}{*}{ 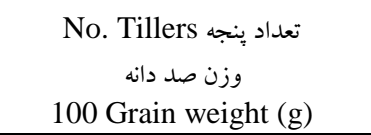 } & $q T N 2$ & RM112-RM5915 & 144.4 & IR & qTN6 & RM7551-RM8239 & 90.8 & IR & 0.78 & 2.1 & - & - & - \\
\hline & $q G W 1-1$ & RM8231-RM8235 & 148.7 & $\mathrm{~A}$ & $q G W 5-1$ & RM5410-RM1237 & 55.6 & IR & -0.08 & 12.4 & - & - & - \\
\hline & $q G W 1-2$ & RM8235-RM5310 & 155.4 & A & $q G W 5-2$ & RM3505-RM421 & 100.1 & IR & -0.07 & 9.1 & - & - & - \\
\hline
\end{tabular}

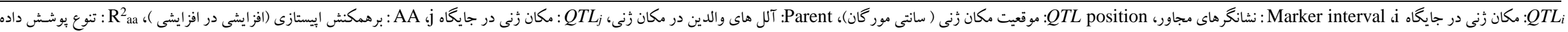

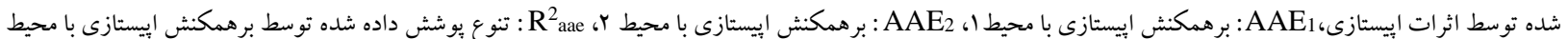




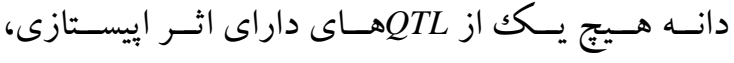

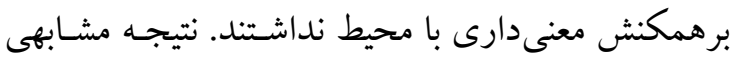

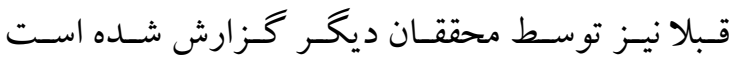

.(Zhuang et al., 2002)

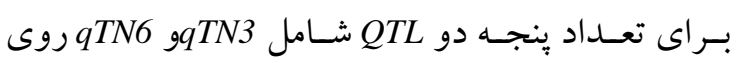

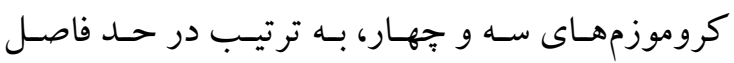

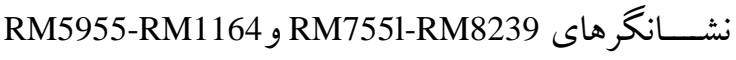

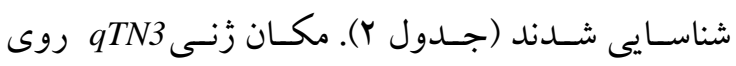

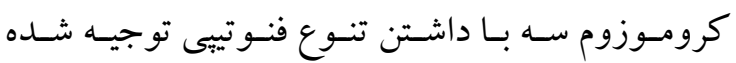

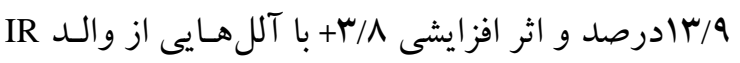

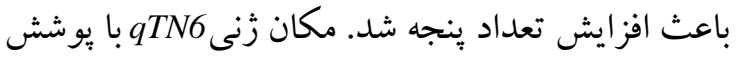

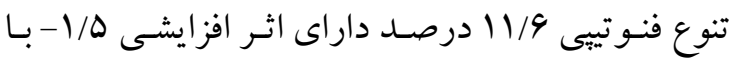

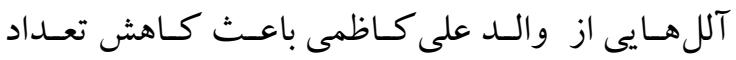

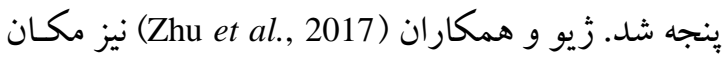

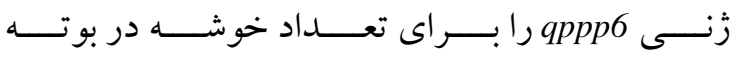

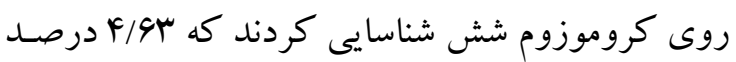

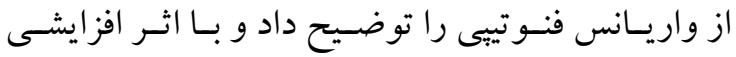

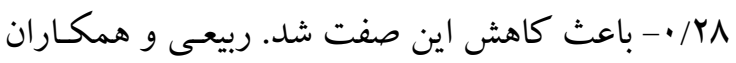
بـ براى تعـداد خوشـه در بو تـه ســ (Rabiei et al., 2013) QTL روى كروموزومهاى يكك، سه و شش شناسايى

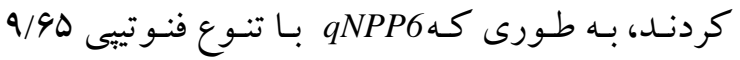

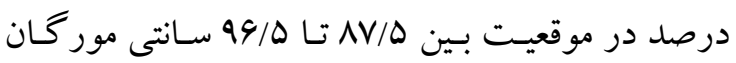

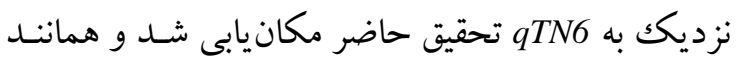

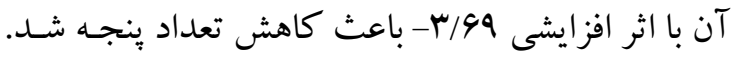
همجنين qNPP3 با تنوع فنـوتييى 19/1 1 درصـد، مشابه

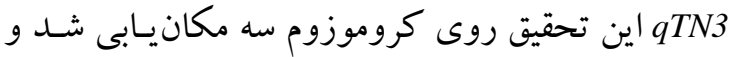

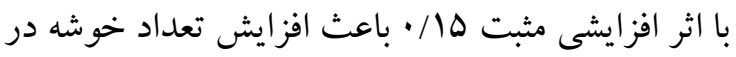
بوته كرديد كه با نتايج تحقيق حاضر مطابقت داشت.

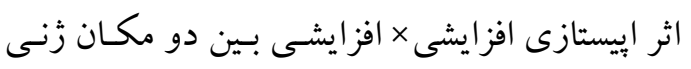

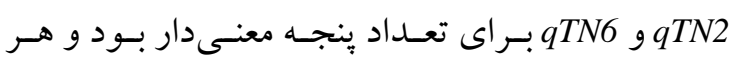

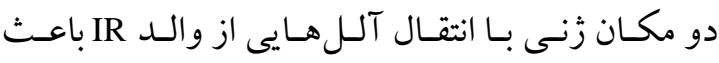

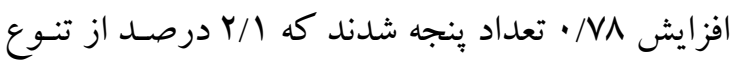

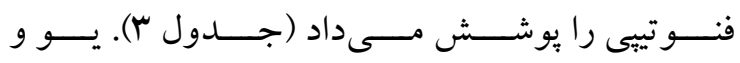
همكـاران(You et al., 2006) تعـدادى QTL إيستـاتيكك
ينج و شش به عنوان QTLهاى اصلى شناسايى نشد، ولى

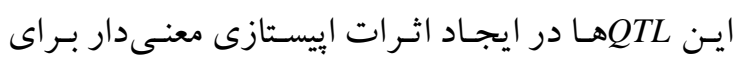

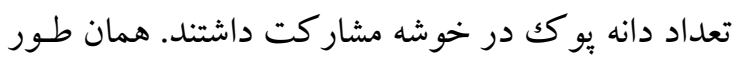
كه ساير محققان نيز اشـاره داشتند (You et al., 2006).

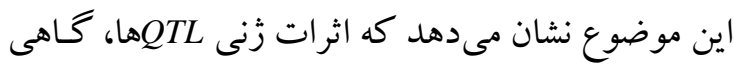

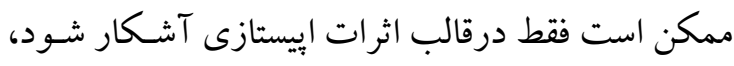

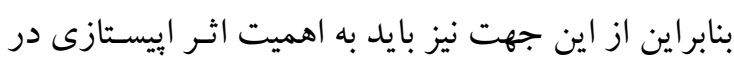
برنامهاى بهنزادى توجه كرد.

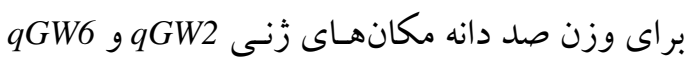

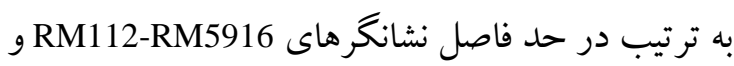

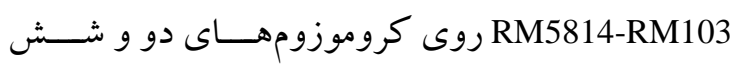
شناسايى شدند (جـدول Y). هـر دو

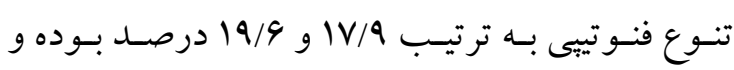

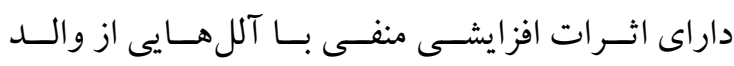

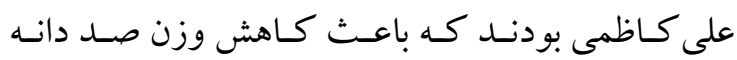

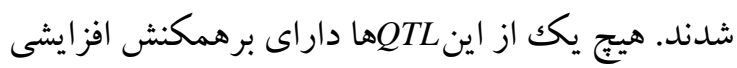
Zا محيط معنى دارى نبودنـلد. زويـو و همكـاران ( (al., 2005 دانه، شش QTL در شرايط آبيارى مناسب و سه QT شرايط تنش آبى مكانيسابى كردنــ كـه

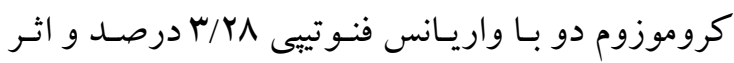

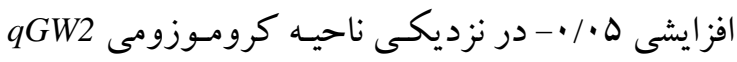

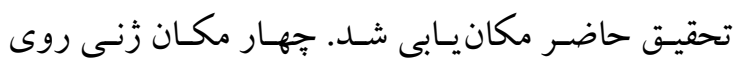
كروموزومهــاى يـكك (دو مـورد) و يـــنج (دو مـوردد)

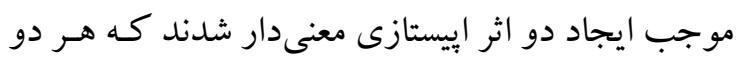

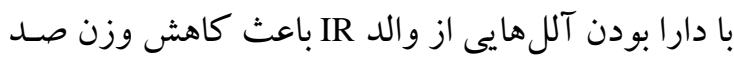

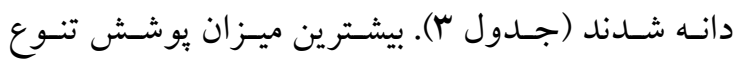

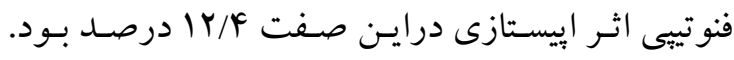

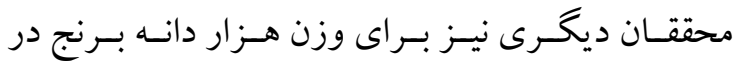

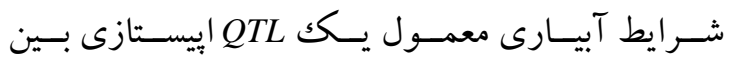

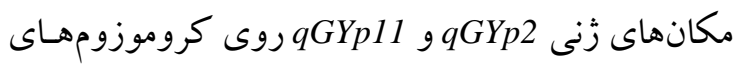

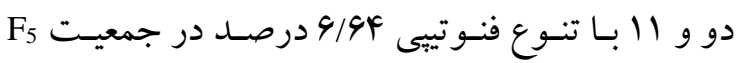

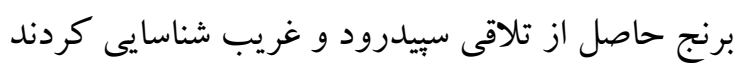

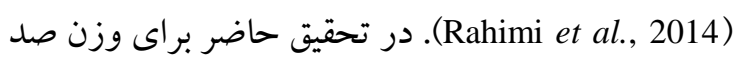




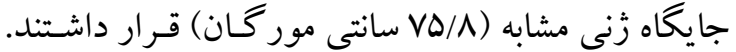

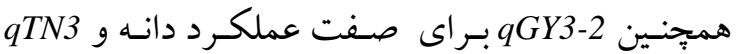
بـراى تعــاد ينجـهـ روى كرومـوزوم سـه در حسـ فاصـل نشانكرهاى RM7551-RM8239 داراى موقعيت يكسان (س/ •9 سانتى مور گان) بودند. سينگ و همكاران نيز (Singh et al., 2017) را براى تعداد ينجه در شرايط غرقاب معمـولى شناسـايى

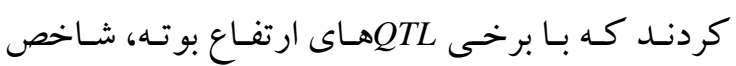
برداشت، تعداد خوشه در بوته و زيست توده ريشه بـرنج

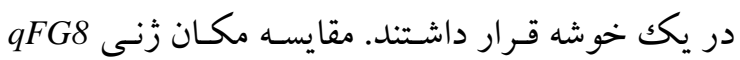
براى تعداد دانه ير در خوشه و qGY8 بر اى عملكرد دانسه نيـز نشـان داد كـه هـر دو مكـان زنسى روى كرومـوزوم

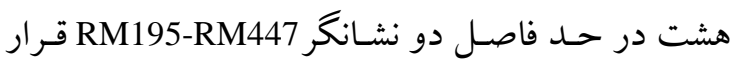
داشتند و موقعيت QTLهاى كاهش دهنده اين دو صفت يكسان (ه/ه • 1 سانتى مور كان) بود.

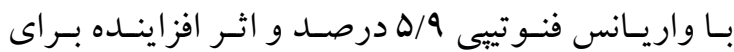
تعـداد خوشـه در بوتـه را شناسـايى كردنســ. در تحقيـق . حاضــر بــراى ايـن صـفت بــرهمكنش اييسـتازى بــا محيط معنى دار مشاهده نشد كه بـا نتيجـه سـاير محققـان (Zhao et al., 2013) زوانگك و همكاران (Zhuang et al., 2002) جهار جفـت إيستاتيك افزايشى × افزايشى (AATL) بـراى تعـداد خوشه در بوته كزارش كردند كه يـك جفــت از آنهـا روى كروموزوم دو داراى برهمكنش اييستازى مثبـت و

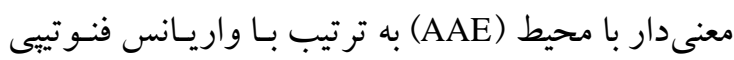

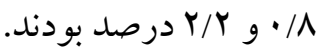
برسى جايگاه QTL هاى اصلى (جدول F) نشـان داد كـه يـك QTL عملكــ Q 1ه/9 درصد و يكك QTL از تعداد ينجه، qTN6 هـردو در حد فاصل نشانكرهـاى RM7551-RM8239 در موقعيـت

جدول F- خوشههاى مكانهاى زنى شناسايى شده براى عملكرد و اجزاى عملكرد برنج در جمعيت على كاظمى /IR در دو مكان

Table 4. QTL clusters identified for grain yield and yield components of rice in Alikazemi/IR population in two locations

\begin{tabular}{|c|c|c|c|}
\hline $\begin{array}{c}\text { كروموزم } \\
\text { Choromosom }\end{array}$ & $\begin{array}{c}\text { نشانگر هاى مجاور } \\
\text { Marker interval }\end{array}$ & صفت & $\begin{array}{l}\text { دامنه يوشش تنوع فنو تييى } \\
\text { Range of } R_{a}^{2}\end{array}$ \\
\hline 3 & RM5955-RM1164 & عملكرد دانه (Yld)، تعداد ينجه (NT) & $13.9-16.6$ \\
\hline 6 & RM7551-RM8239 & عملكر د دانه (Yld)، تعداد ينجه (NT) & $11.6-15.6$ \\
\hline 8 & RM195-RM447 & عملكرد دانه (Yld)، تعداد دانه بِر در خوشه (NFg) & $14.5-18.5$ \\
\hline
\end{tabular}

نيازمند كار، زمان و هزينه بيشتر با احتمال عدم موفقيـت بـالاتر اسـت، باعـث بهبـود جنــدين صـفت مـرتبط بـا

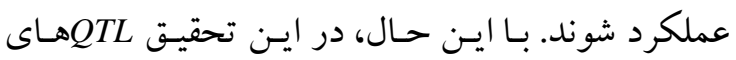
يليو تروييكك داراى اثرات افزايشى مطلـوب بـراى تمـام صفات هر خوشـه نبودنـد، بـه عنـوان مثـال خوشـه روى

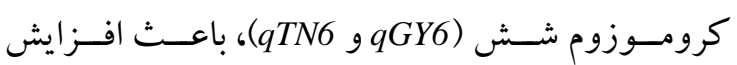

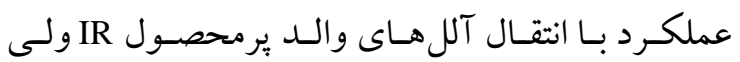
كاهش تعداد ينجه با آلل هاى والد كم ينجه على كاظمى شد. بعلاوه خوشه روى كروموزوم سـه(qGY3 و qTN3) باعث افزايش تعداد ينجه بـا آلل هــاى والــ برينجـه IIR،
تـأثير همزمـان يـك QTL بـه صسورت خوشـه بـر دو يا جند صفت مى تواند احتمالا به دليل بيوسـتِى شـديد مكـانهـاى زنسى متفـاوت كنتـرل كنتـده ايسن صـفات و يا اثر يليوترويى يكك مكان زنى باشد كه بطور همزمـان

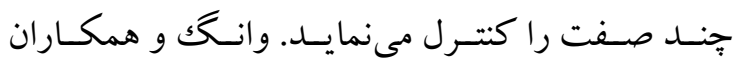

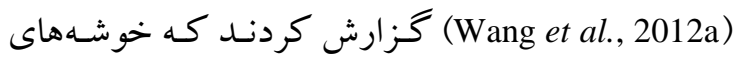

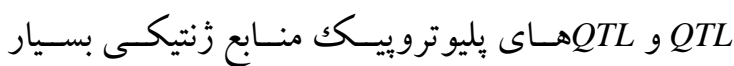
ارزشمندى در بهنز ادى مولكولى براى افز ايش عملكرد

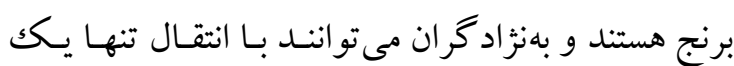

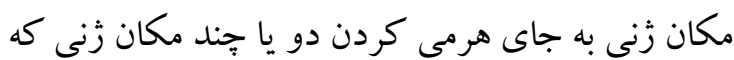


توسـعه ارقـام يرمحصـول از طريـق بـه نـز ادى مولكـولى

بسيار مهم و ضرورى هستند (Zhang et al., 2018).

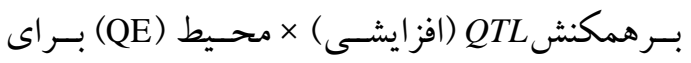
عملكرد دانه و تعداد دانه بوكك در خوشه معنىى دار بـود كه نشان داد QTLهـاى مـرتبط در محيطهـاى مختلـف، باعـث ايجـاد نوسـاناتى در ايـن صـفات شـده و بنـابراين

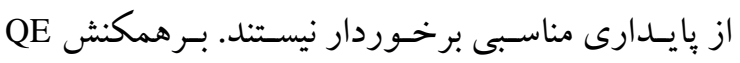
براى بقيه صفات معنى دار نبود و نشان داد كه QTLهـاى اين صـفات جنــدان تحـت تـاثير محسيط نبودنـد. وجـود برهمكنش Qعنى Q معار در برخسى صـفات و معنىدار

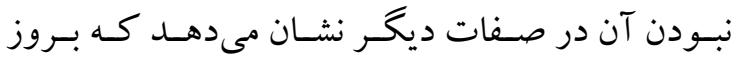
برهمكنش QE به نوع صفت نيز بستكى دارد، به طورى

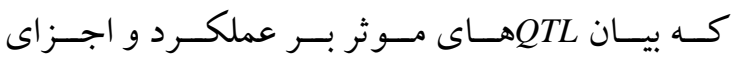

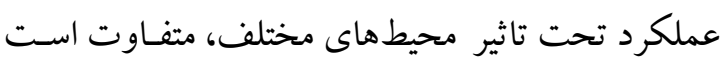
و و (Wang et al., 2012a) برهمكنش احتمالا يايدارتر هستند. در اين تحقيق در مجموع \1 جفت QTL إيستاتيك با اثر افزايشى × افزايشى معنى دار براى ينج صفات مورد مطالعـه شناسـايى شــند. مقايسـه QTLهــاى اصـلمى و إيستاتيكك نشان داد كه دامنه تنوع فنـوتييى توجيسه شـده

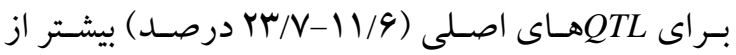
هـاى اييسـتاتيكك (Y QTL موضوع نشان داد كه برخى از QTLهاى اييستاتيك سهم قابل توجهى از واريانس فنوتيبى صفات مورد مطالعـه را توجيه كردند، بنابراين بايد تاثير ايستازى مطلـوب را در

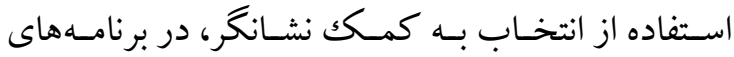
بلنزادى برنج مد نظر قرار داد. بعلاوه در برخى از جفـت هاى مشاركت كننده در اييستازى هـر دو QTL بــــ عنوان QTL اصلى شناسايى شده بودند، در حالى كـه در برخى موارد يكى از جفت QTLها يا هيجيـك از آنهـا

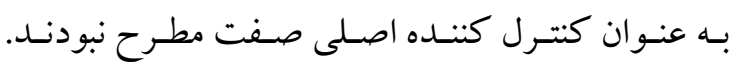

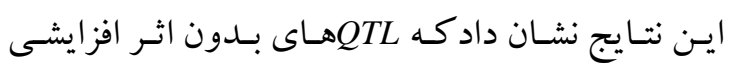

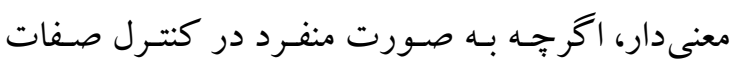
تاثير ندارند، ولى نقش مهمى در بـروز اثـرات إيسـتازى
ولى كاهش عملكرد دانه با آلل هاى والـد كـم محصـول على كاظمى شد. بنـابراين مسى تـوان كفـت كـه صـفات ايسن دو خوشـه احتمــالا تحست تـاثير بيوسـتحى زنسى قرار داشتند. بهر حال افزايش كارايى هرمى كردن زنهـا بـر اى بهبـود صـفات تر كيبى نيـاز بــه اطلاعـات دقيـقتر

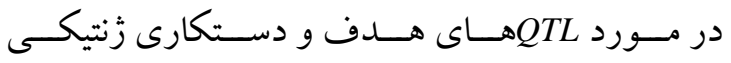
متمر كـز در ناحيسه زنسى اختصاصسى ايسن QTLهــا دارد

.(Wang et al., 2012b)

\section{نتيجه كيرى}

در ايـن تحقيـق در مجمـوع سا QTL اصـلى بــراى عملكرد دانه و اجـزاى عملكـرد بـرنج شناسـايى شـدند.

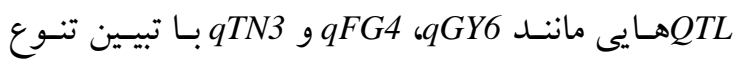

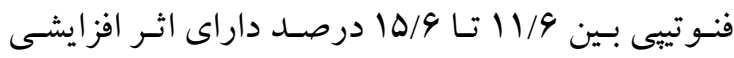
مثبت و افزاينده صفت و qSG1 بـا توجيـه تنـوع فنـوتييى 19/9 درصد داراى اثر افزايشى منفى و كاهنـده صـفت آن بودند كه نشان دهنده انتقال آللهاى مطلوب بـراى ايسن صفات از والد IR يا والد على كاظمى به نتـاج اسـت. در نتيجه اين QTLهاى اصلى مى توانند براى بهبود عملكرد دانه مورد توجه بهنزاد كران قرار بكيرند. بهعلاوه نشـانكر

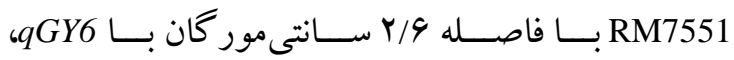
نشانكر هاى RM8212 و RM3417 با فاصـله يـك و يــنج

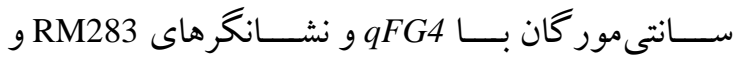

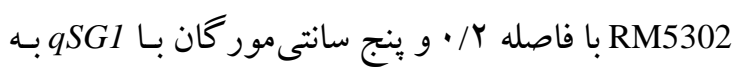

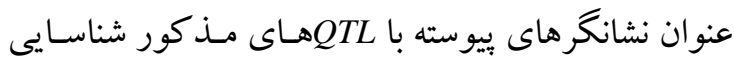

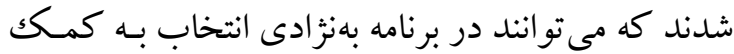

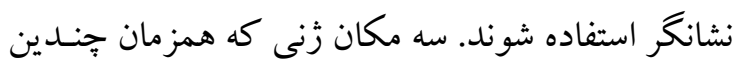
صفت را كنترل مى كردند، به صسورت خوشهه زنسى بـين عملكرد دانه با تعداد ينجه روى كروموزوم سه و شش و بين عملكرد و تعداد دانه ير در خوشـه روى كرومـوزوم هشت در موقعيت كروموزومى يكسان شناسـايى شـدند. محققان برنج كَزارش كردهانـد كـه شناسـايى زنهـا يـا

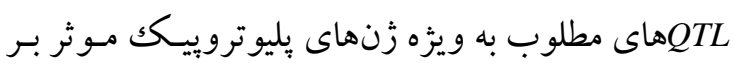
صفات مرتبط با عملكرد از زرم پِلاسمهاى بـرنج، بـراى 
نـوع و انسـازه جمعيـت و نشـانكرهاى مولكـولى مـورد

استفاده باشــ Hosseini Chaleshtari et al., 2012; .Rabiei et al., 2013; Zhao et al., 2013) اين تخقيقات تعـدادى از QRTLهـا نيـز در ناحيـه مشـابهى روى يكك كروموزوم كزارش شدند كه مىتوانـد نشـان

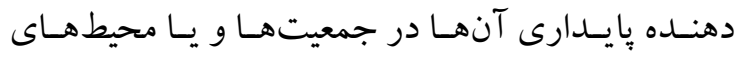
مختلف باشد. علاوه براين، مطالعات مكانيـابى QTLهـا در سالهاى اخير نشان داده اسـت كـه اثـرات إيسـتازى نقش مهمى رابر اي صفات كمى مانتـد عملكـرد دانـه و اجزاى عملكرد برنج ايفا مى كنند و بايــد آنهـا را مـورد توجه قرار داد.$$
\text { سياسگز ارى }
$$

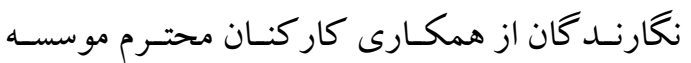$$
\text { تحقيقات برنج كشور، بويزه بخـش تحقيقـات اصـلاح و }
$$

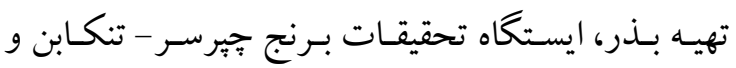$$
\text { دانشكده كشاورزى دانشخاه لرسـتان صـميمانه تقـدير و }
$$$$
\text { تشكر مى نمايند. }
$$

$$
\text { ايفا نموده و بـر صـفات مـورد مطالعـه تـاثير مى كذارنـد }
$$
و نبايسـ آنهـا را ناديـده كرفت. همجنين مى توان كفت كه بروز إيستازى بسته به محيط مورد بررسى، متفاوت است. در ايسن تحقيـق فقـط يـك

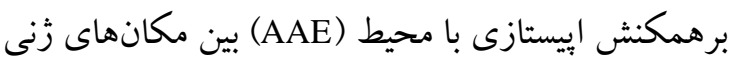

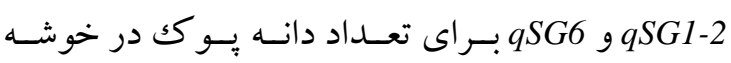

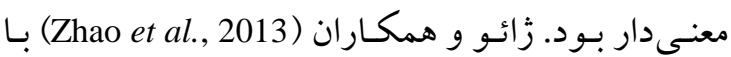
ارزيابى MM لاين از يكك جمعيت RIL بـرنج حاصـل از تلاقى يكك رقم اينـديكاى Luhui 99 و رقـم زايونيكـاى Nipponbare كزارش كردند كه هيج يكك از صـفات عملكـرد دانه و اجزاى مرتبط بـا عملكـرد، داراى بـرهمكنش ابيسـتازى

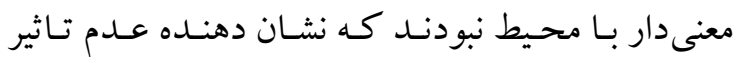
محيط بر QTLهاى إيستاتيكك بوده است.

مقايسه نتـايج تحقيـق حاضـر بـا آزمايشهـاى انجـام

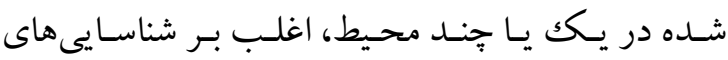
هاى متفاوت دلالت داشـت كـه مى توانـد ناشـى از برهمكنش آنها بـا محـيط، زمينه زنتيكى، تفـاوت در

\section{References}

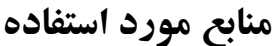

Chaudhary, R. C. 1996. Standard Evaluation System for Rice. International Rice Research Institute, Manila. Philippines.

Hosseini Chaleshtari, M., S. Houshmand, S. Mohammadi, A. Tarang, M. Khoddambashi and H. R. Soroush. 2012. Mapping quantitative trait loci for plant height, heading time, growth duration and grain yield in two advanced back cross populations of rice. Iran. J. Crop Sci. 14(3): 235-249. (In Persian with English abstract).

Hosseini Chaleshtari, M., H. Rahimsourosh and S. Houshmand. 2014. Estimation of epistasis and interaction with environment to control of rice yield over four years. First International and $13^{\text {th }}$ National Iranian Crop Science Congress, 26-28 Aug. 2014, Karaj, Iran. (In Persian with English abstract).

Hosseini, M., S. Houshmand, S. Mohamadi, A. Tarang, M. Khodambashi and H. Rahimsoroush. 2012. Detection of QTLs with main, epistatic and QTL $\times$ environment interaction effects for rice grain appearance quality traits using two populations of backcross inbred lines (BILs). Field Crops Res. 135: 97-106.

Manly, K. F., R. H. Cudmore Jr and J. M. Meer. 2001. Map Manager QTX, cross-platform software for genetic mapping. Mammalian Genome. 12: 930-932.

McCouch, S. R., L. Teytelman, Y. Xu, K. B. Lobos, K. Clare, M. Walton, B. Fu, R. Maghirang, Z. Li and Y. Xing. 


$$
\text { "نشريه علوم زراعى ايران"، جلد بيست و يكم، شماره F، زمستان 19سا }
$$

2002. Development and mapping of 2240 new SSR markers for rice (Oryza sativa L.). DNA Res. 9: 199-207.

Murray, M. G. and W. F. Thompson. 1980. Rapid isolation of high molecular weight plant DNA. Nucleic Acids Res. 8: 4321-4326.

Rabiei, B., M. Masaeli and A. Tarang. 2013. Identification of QTLs for grain yield and yield component in rice (Oryza sativa L.). Iran. J. Field Crop Sci. 44: 293-304. (In Persian with English abstract).

Rabiei, B., M. Valizadeh, B. Ghareyazie, M. Moghaddam and A. Ali. 2004. Identification of QTLs for rice grain size and shape of Iranian cultivars using SSR markers. Euphytica. 137: 325-332.

Rahimi, M., B. Rabiei, H. Dehghani and A. Tarang. 2014. Mapping main and epistatic QTLs for drought tolerance indices in F5 population of rice. New Genetic J. 4: 435-448.

Sabouri, A., M. Toorchi, B. Rabiei, S. Aharizad, A. Moumeni and R. Singh. 2010. Identification and mapping of QTLs for agronomic traits in indica-indica cross of rice (Oryza sativa L.). Cereal Res. Commun. 38: 317-326.

Satagopan, J. M., B. S. Yandell, M. A. Newton and T. C. Osborn. 1996. A Bayesian approach to detect quantitative trait loci using Markov Chain Monte Carlo. Genetics. 144: 805-816.

Singh, A., J. Carandang, Z. J. C. Gonzaga, B. C. Collard, A. M. Ismail and E. M. Septiningsih. 2017. Identification of QTLs for yield and agronomic traits in rice under stagnant flooding conditions. Rice. 10: 15.

Temnykh, S., W. D. Park, N. Ayres, S. Cartinhour, N. Hauck, L. Lipovich, Y. G. Cho, T. Ishii and S. R. McCouch. 2000. Mapping and genome organization of microsatellite sequences in rice (Oryza sativa L.). Theor. Appl. Genet. 100: 697-712.

Thomson, M., T. Tai, A. McClung, X. Lai, M. Hinga, K. Lobos, Y. Xu, C. Martinez and S. R. McCouch. 2003. Mapping quantitative trait loci for yield, yield components and morphological traits in an advanced backcross population between Oryza rufipogon and the Oryza sativa cultivar Jefferson. Theor. Appl. Genet. 107: 479-493.

Wang, C., J. Rutledge and D. Gianola. 1994. Bayesian analysis of mixed linear models via Gibbs sampling with an application to litter size in Iberian pigs. Genet. Select. Evol. 26: 91.

Wang, D., J. Zhu, Z. Li and A. Paterson. 1999. Mapping QTLs with epistatic effects and QTLx environment interactions by mixed linear model approaches. Theor. Appl. Genet. 99: 1255-1264.

Wang, P., Y. Xing, Z. Li and S. Yu. 2012a. Improving rice yield and quality by QTL pyramiding. Mol. Breed. 29: 903-913.

Wang, P., G. Zhou, K. Cui, Z. Li and S. Yu. 2012b. Clustered QTL for source leaf size and yield traits in rice (Oryza sativa L.). Mol. Breed. 29: 99-113.

Wang, X., Y. Pang, J. Zhang, Q. Zhang, Y. Tao, B. Feng, T. Zheng, J. Xu and Z. Li. 2014. Genetic background effects on QTL and QTLx environment interaction for yield and its component traits as revealed by reciprocal introgression lines in rice. The Crop J. 2: 345-357.

Wu, B., Z. Han and Y. Xing, 2013. Genome Mapping, Markers and QTLs. In: Q. Zhang and R.A. Wing (Eds.), Genetics and Genomics of Rice. Crops and Models, vol 5. Springer, New York, NY.

Xing, Y., Y. Tan, J. Hua, X. Sun, C. Xu and Q. Zhang. 2002. Characterization of the main effects, epistatic 


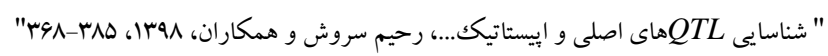

effects and their environmental interactions of QTLs on the genetic basis of yield traits in rice. Theor. Appl. Genet. 105: 248-257.

Yang, J., C. Hu, H. Hu, R. Yu, Z. Xia, X. Ye and J. Zhu. 2008. QTLNetwork: mapping and visualizing genetic architecture of complex traits in experimental populations. Bioinformatics. 24: 721-723.

Yang, J. and J. Zhu. 2005. Methods for predicting superior genotypes under multiple environments based on QTL effects. Theor. Appl. Genet. 110: 1268-1274.

Ye, Z., J. Wang, Q. Liu, M. Zhang, K. Zou and X. Fu. 2009. Genetic relationships among panicle characteristics of rice (Oryza sativa L.) using unconditional and conditional QTL analyses. J. Plant Biol. 52: 259-267.

You, A., X. Lu, H. Jin, X. Ren, K. Liu, G. Yang, H. Yang, L. Zhu and G. He. 2006. Identification of quantitative trait loci across recombinant inbred lines and testcross populations for traits of agronomic importance in rice. Genetics. 172: 1287-1300.

Yue, F., Z. Rong-rong, L. Ze-chuan, C. Li-yong, W. Xing-hua and C. Shi-hua. 2015. Quantitative trait locus analysis for rice yield traits under two nitrogen levels. Rice Sci. 22: 108-115.

Zhang, J., X. Ou, H. Hu, B. Du, W. Lv, L. Yang, D. Xing, J. Xu, X. Qiu and T. Zheng. 2018. Identification of $Q T L s$ for yield-related traits using two sets of introgression lines with a common donor parent in rice. Int. J. Agric. Biol. 20: 15-24.

Zhao, F., H. Zhu, R. Zeng, G. Zhang and S. Xu. 2016. Detection of additive and additivex environment interaction effects of QTLs for yield-component traits of rice using single-segment substitution lines (SSSLs). Plant Breed. 135: 452-458.

Zhao, J., K. Jiang, L. Yang, Q. Yang, X. Wan, Y. Cao, S. You, J. LUO, T. ZHANG and J. Zheng. 2013. QTL mapping for yield related components in a RIL population of rice. Chinese J. Rice Sci. 27: 344-352.

Zhu, M., D. Liu, W. Liu, D. Li, Y. Liao, J. Li, C. Fu, F. Fu, H. Huang and X. Zeng. 2017. QTL mapping using an ultra-high-density SNP map reveals a major locus for grain yield in an elite rice restorer R998. Sci. Reports. 7: 10914.

Zhuang, J. Y., Y. Y. Fan, Z. M. Rao, J. L. Wu, Y. W. Xia and K. L. Zheng. 2002. Analysis on additive effects and additive-by-additive epistatic effects of QTLs for yield traits in a recombinant inbred line population of rice. Theor. Appl. Genet. 105: 1137-1145.

Zou, G., H. Mei, H. Liu, G. Liu, S. Hu, X. Yu, M. Li, J. Wu and L. Luo. 2005. Grain yield responses to moisture regimes in a rice population: association among traits and genetic markers. Theor. Appl. Genet. 112: 106-113. 


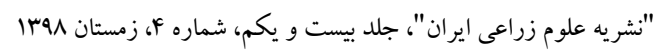

\title{
Identification of main and epistatic $Q T L s$ for grain yield related traits in a recombinant inbred lines population of rice (Oryza sativa L.)
}

\author{
Rahimsoroush, H. ${ }^{1}$, F. Nazarian Firouzabadi², M. Hosseini Chaleshtari ${ }^{3}$, A. \\ Esmaeili $^{4}$ and A. A. Ebadi ${ }^{5}$
}

\begin{abstract}
Rahimsoroush, H., F. Nazarian Firouzabadi, M, Hosseini Chaleshtari, A. Esmaeili and A. A. Ebadi. 2020. Identification of main and epistatic $Q T L S$ for grain yield related traits in a recombinant inbred lines population of rice (Oryza sativa L.). Iranian Journal of Crop Sciences. 21(4): 368-385. (In Persian).
\end{abstract}

Rice yield as a complex trait is the main target in most rice breeding programs. To map the main and epistatic QTLs controlling grain yield and yield components, an experiment was carried out using a $129 \mathrm{~F}_{6}$ recombinant inbred lines population (IRA population) originated from a cross between Alikazemi / IR67017-180-2-1-2, in 2015 growing season in two locations, Rasht and Tonekabon, Iran. The experimental design was augmented design arrangment with five check cultivars in randomized complete block design with five replications. Analysis of variance showed that the linkage map consisted of 87 Single Sequence Repeats (SSRs) covering $1356.0 \mathrm{cM}$ of rice genome in 12 linkage groups with an average distance of $15.58 \mathrm{cM}$ spamming two markers. The results of combined analysis of variance for two locations, using composite interval mapping method, identified a total of 13 main QTLs on rice chromosomes for five measured traits. The qTN3 with $13.9 \%$ for tiller number per plant, the $q F G 4$ with $11.6 \%$ for filled grain per panicle and the $q G Y 6$ with $15.6 \%$ for grain yield had significant positive additive effect. Furthermore, the $q S G l$ with $19.9 \%$ phenotypivc variation had a negative additive effect on the number of unfilled grain.panicle ${ }^{-1}$. These finding suggest that these $Q T L s$ can be used in rice breeding programs for improving grain yield. The interaction between additive effect (A) of QTLs and environment (E) was significant on grain yield and number of unfilled grain.panicle ${ }^{-1}$, but it was not significan on other traits. A total of 18 QTL pairs with significant additive $\times$ additive (AA) epistatic effect were identified for all traits. The highest epistasic effects were related to grain yield and number of unfilled grain.panicle ${ }^{-1}$ with six pairs of QTLs for each of these traits. Only one of the epistatic effects between $q S G 1-2$ and $q S G 6$ had significant $\mathrm{AAE}$ effect with a $\mathrm{R}_{\text {aae }}^{2}=$ of $3.4 \%$. In addition, some $Q T L s$ were identified as three gene clusters controlling the grain yield, number of tiller.plant ${ }^{-1}$ and number of filled grain.panicle ${ }^{-1}$. Furthermore, five microsatellite markers including RM7551, RM8218-RM3417 and RM5302- RM283 0.2 to 5 cM distance from were identified as linked markers with $q G Y 6, q F G 4$ and $q S G 1$, respectively. These markers can be considered in the marker-assisted rice breeding program.

Key words: Epistasis, Gene cluster, Phenotypic variation, QTL mapping and Rice.

\footnotetext{
Received: April, 2019 Accepted: September, 2019

1. PhD Student, Lorestan University, Khorramabad, Iran

2. Pofessor, Lorestan University, Khorramabad, Iran (Corresponding author) (Email: nazarian_f2000@ yahoo.com)

3. Assistant Prof., Rice Research Institute of Iran, Agricultural Research, Education and Extension Organization, Iran

4. Associated Prof., Lorestan University, Khorramabad, Iran

5. Assistant Prof., Rice Research Institute of Iran, Agricultural Research, Education and Extension Organization, Iran
} 